\title{
$A b$ initio derived analytical fits of the two lowest triplet potential energy surfaces and theoretical rate constants for the $\mathrm{N}\left({ }^{4} S\right)+\mathrm{NO}\left(X^{2} \Pi\right)$ system
}

\author{
P. Gamallo, Miguel González, ${ }^{\text {a) }}$ and R. Sayós ${ }^{\text {b) }}$ \\ Departament de Química Física i Centre de Recerca en Química Teòrica, Universitat de Barcelona, \\ C. Martí i Franquès 1, 08028 Barcelona, Spain
}

(Received 11 March 2003; accepted 2 May 2003)

\begin{abstract}
This work presents two new analytical fits of the ground potential energy surface (PES) $\left({ }^{3} A^{\prime \prime}\right)$ and the first excited PES $\left({ }^{3} A^{\prime}\right)$ involved in the title reaction, considering the $\mathrm{N}$-abstraction (1) and the O-abstraction (2) reaction channels, and the reverse reaction $(-1)$. The PESs are derived from $a b$ initio electronic structure calculations by means of second-order perturbation theory on a complete active-space self-consistent-field wave function (CASPT2 method). Stationary points and extensive grids of ab initio points (about 5600 points for the ${ }^{3} A^{\prime \prime}$ PES and 4900 points for the ${ }^{3} A^{\prime}$ PES) were fitted along with some diatomic spectroscopic data to better account for the experimental exoergicity. Thermal rate constants were calculated $(200-5000 \mathrm{~K})$ for all mentioned reaction processes by means of the variational transition-state theory with the inclusion of a semiclassical tunneling correction. Excellent agreement with the experimental data was observed for reaction (1) and its reverse, within all the temperature range, substantially improving the results derived from previous analytical PESs. The contribution of the ${ }^{3} A^{\prime}$ PES to the reaction rate constant $\left(k_{1}\right)$ was small even at high temperatures (e.g., only $10.8 \%$ at $2500 \mathrm{~K}$ ). Moreover, the main contribution to reaction rate constant $\left(k_{2}\right)$ was due to the ${ }^{3} A^{\prime}$ PES, differing from what happens for reaction (1). The O-abstraction reaction channel accounts for a 3.0\% of the total reaction $\left(k=k_{1}+k_{2}\right)$ at $5000 \mathrm{~K}$, consistent with the very limited experimental information available. (C) 2003 American Institute of Physics. [DOI: 10.1063/1.1586251]
\end{abstract}

\section{INTRODUCTION}

The elementary gas-phase reaction of ground atomic nitrogen with nitric oxide, ${ }^{1}$

$$
\begin{aligned}
\mathrm{N}\left({ }^{4} S\right)+\mathrm{NO}\left(X^{2} \Pi\right) & \rightarrow \mathrm{O}\left({ }^{3} P\right)+\mathrm{N}_{2}\left(X^{1} \Sigma_{g}^{+}\right) \Delta_{r} H_{0 \mathrm{~K}}^{\circ} \\
& =-75.01 \mathrm{kcal} / \mathrm{mol},
\end{aligned}
$$

and its reverse reaction are of interest in atmospheric chemistry. Reaction (1) is thought to be the dominant removal step for odd nitrogen in the upper stratosphere, the mesosphere, and the thermosphere of the Earth and, possibly, also in Mars and Venus. ${ }^{2-4}$ The precision of the rate constants for this reaction over a wide range of temperatures [e.g., from $185 \mathrm{~K}$ in mesopause to approximately $1000 \mathrm{~K}$ at $250 \mathrm{~km}$ of altitude (upper thermosphere) (Ref. 5)] is of great interest for modeling the concentration of $\mathrm{NO}_{x}$ species in these atmospheric regions for different levels of solar activity. Moreover, this reaction has been also proposed as one important step to remove the NO molecules produced in some heterogeneous catalytic processes (e.g., in $\mathrm{SiO}_{2}$-based materials) for airflow cases. ${ }^{6}$ The reverse reaction is as well one of the two steps of the Zeldovich mechanism which produces NO, and it is very important for accurate modeling of thermochemical phenomena in rarefied atmospheric flows. A good understanding of the vibrationally and rotationally hot NO molecules pro-

\footnotetext{
a)Electronic mail: miguel@qf.ub.es

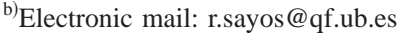

duced by the reverse reaction is necessary to establish appropriately the heat flux on the thermal protection systems used in atmospheric reentry vehicles (e.g., American space shuttle, Japanese orbital reentry experiment, etc.).

Reaction (1) has been the object of abundant kinetic studies over several temperature ranges, but these studies present significant discrepancies, possibly due to its slight temperature dependence. Table I reports a brief summary of some of the main Arrhenius expressions for the experimental rate constants. A small activation energy $(0.8-1.6 \mathrm{kcal} / \mathrm{mol})$ or even a negative value $(-0.2$ to $-0.3 \mathrm{kcal} / \mathrm{mol})$ were reported in these works. Direct kinetic data for the reverse endothermic reaction have also been obtained mainly at high temperatures $(T>2000 \mathrm{~K}){ }^{8}$ and they are more coincident than in the case of the direct reaction.

There are very few experimental studies dealing with the dynamic properties of reaction (1) or about its reverse $(-1)$. Very early studies showed a product $\mathrm{N}_{2}$ average vibrational energy fraction of $0.25-0.28 .^{10,11}$ However, another past study indicated $75 \% \pm 5 \%$ of the $\mathrm{N}_{2}$ molecules appeared with $v^{\prime}>4 .^{12}$ To the best of our knowledge, there are no experimental dynamics studies on the reverse reaction. However, theoretical studies are available on both reactions. In earlier studies we presented several theoretical approaches for reaction (1), and we also gave a wide review of the main experimental and theoretical data that had been published for this reaction. We developed an analytical potential energy surface $^{13}$ (PES) based on limited ab initio information ${ }^{14}$ for 
TABLE I. Experimental kinetic data for the $\mathrm{N}\left({ }^{4} S\right)+\mathrm{NO} \rightarrow \mathrm{O}\left({ }^{3} P\right)+\mathrm{N}_{2}$ reaction.

\begin{tabular}{llll}
\hline \hline Reference & $k_{1}(T)\left(\mathrm{cm}^{3}\right.$ molecule $\left.{ }^{-1} \mathrm{~s}^{-1}\right)$ & $T(\mathrm{~K})$ & Method $^{\mathrm{a}}$ \\
\hline $\begin{array}{c}\text { Clyne and } \\
\text { McDermid }\end{array}$ & $(8.2 \pm 1.4) \times 10^{-11} \mathrm{e}^{-410 \pm 120 / T}$ & $298-670$ & DF-MS \\
$\begin{array}{c}\text { Siskind and } \\
\text { Rusch }\end{array}$ & $1.6 \times 10^{-10} \mathrm{e}^{-460 \pm 60 / T}$ & $>300$ & review \\
$\begin{array}{c}\text { Wennberg } \\
\quad \text { et al. }\end{array}$ & $(2.2 \pm 0.2) \times 10^{-11} \mathrm{e}^{160 \pm 50 / T}$ & $213-369$ & DF-RF \\
$\begin{array}{c}\text { Baulch } \\
\text { et al. }\end{array}$ & $7.1 \times 10^{-11} \mathrm{e}^{-790 / T}$ & $1400-4000$ & review \\
$\begin{array}{c}\text { DeMore } \\
\text { et al. }\end{array}$ & $2.1 \times 10^{-11} \mathrm{e}^{100 \pm 100 / T}$ & $200-400$ & review \\
\hline \hline
\end{tabular}

${ }^{\mathrm{a} D F}$ (discharge flow), MS (mass spectrometry), and RF (resonance fluorescence).

${ }^{\mathrm{b}}$ Reference 7 .

${ }^{\mathrm{c}}$ Reference 2 .

${ }^{\mathrm{d}}$ Reference 3 .

${ }^{\mathrm{e}}$ Reference 8 , with an error: $\Delta \log k= \pm 0.2$. Data for its reverse reaction are also reported: $3.0 \times 10^{-10} \mathrm{e}^{-38300 / T}(1400-4000 \mathrm{~K})$.

${ }^{\mathrm{f}}$ Reference 9 .

the ground ${ }^{3} A$ " PES. In addition, we also performed dynamical studies on reaction (1) by means of the quasiclassical trajectory $(\mathrm{QCT})$ method, ${ }^{15}$ reduced quantum mechanical approaches, ${ }^{16}$ and simple models. ${ }^{17}$ Recently, QCT calculations on a new ${ }^{3} A^{\prime \prime}$ PES, ${ }^{18}$ which fitted the same aforementioned $a b$ initio data, ${ }^{14}$ but adding interpolated semiempirical points, reported good thermal rate constants for the 200$1000 \mathrm{~K}$ temperature range. In that work the authors considered the inclusion of a reactant statistical degeneracy factor excluding the NO spin-orbit correction (i.e., 3/16), missing in previous works. These authors also carried out a QCT study ${ }^{19}$ on this reaction, taking into account the first excited PES $\left({ }^{3} A^{\prime}\right)$, previously fitted for the reverse reaction by other authors. ${ }^{20}$ It was concluded that the excited PES became important for reaction (1) only at high energies $(1-3 \mathrm{eV})$. Several theoretical studies on the reverse reaction, using these analytical PESs $\left({ }^{3} A^{\prime \prime}\right.$ and $\left.{ }^{3} A^{\prime}\right)$, produced thermal rate constants and product energy distributions at very high temperatures (i.e., 3000-20000 K), for both thermodynamic equilibrium ${ }^{20}$ and nonequilibrium conditions. ${ }^{21}$

In addition to reaction (1), a second reaction channel involving the $\mathrm{O}$-abstraction process,

$$
\begin{aligned}
\mathrm{N}\left({ }^{4} S\right)+\mathrm{N}^{\prime} \mathrm{O}\left(X^{2} \Pi\right) & \rightarrow \mathrm{N}^{\prime}\left({ }^{4} S\right)+\mathrm{NO}\left(X^{2} \Pi\right) \Delta_{r} H_{0 \mathrm{~K}}^{\circ} \\
& =0 \mathrm{kcal} / \mathrm{mol},
\end{aligned}
$$

can be produced. There is almost no information about it. Some experiments ${ }^{22,23}$ at very high energies with ${ }^{13} \mathrm{~N}$ and pure NO have indicated that reaction channel 2 yielding ${ }^{13} \mathrm{NO}$ could account for up to a $20 \%$ of the total reactivity of this system, though with the possible contribution of the first excited states of nitrogen $\left[\mathrm{N}\left({ }^{2} D,{ }^{2} P\right)\right]$. Nevertheless, there are neither kinetic nor dynamic data about this reaction.

In a recent study of our own (hereafter called paper I) ${ }^{24}$ we have made an extensive $a b$ initio characterization of the stationary points of the lowest ${ }^{3} A^{\prime \prime}$ and ${ }^{3} A^{\prime}$ PESs. According to this study, reaction (1) should be much more important than reaction (2), which should only contribute to reactivity at high collision energies (e.g., over $30 \mathrm{kcal} / \mathrm{mol}$ ). Moreover, we confirmed that the ${ }^{3} A^{\prime \prime}$ PES had no energy barrier for reaction (1) and that the ${ }^{3} A^{\prime}$ PES had an energy barrier (TS1) much lower than the previous ab initio reported value. ${ }^{14}$ Both PESs showed the presence of a minimum (MIN1) and a transition state (TS2) in the minimum energy path (MEP) for reaction (2).

Here we present new analytical PESs for both ${ }^{3} A^{\prime \prime}$ and ${ }^{3} A^{\prime}$ states, based on the high-level $a b$ initio data published in paper I, along with additional grids of ab initio points now calculated. These new PESs will provide better kinetic and dynamical data, and also will allow a deeper understanding of the two reaction channels involved in the title reaction. Furthermore, these PESs will be useful in the study of the reverse reaction in the nonequilibrium conditions of atmospheric reentry vehicles.

This paper is organized as follows: the ab initio method, the fitting procedure, and the derived analytical PESs are described in Sec. II, several variational transition-state theory calculations on thermal rate constants are presented in Sec. III, and finally Sec. IV contains the main concluding remarks.

\section{ANALYTICAL POTENTIAL ENERGY SURFACES}

\section{A. $A b$ initio molecular structure and surface fitting methods}

We have carried out the calculation of grids of ab initio points for both PESs following the main ab initio method used in paper $\mathrm{I}^{24}$ Thus the complete active-space selfconsistent-field (CASSCF) method ${ }^{25,26}$ was used, always including the lowest root in $C_{s}$ symmetry for both triplet PESs (i.e., ${ }^{3} A^{\prime}$ and ${ }^{3} A^{\prime \prime}$ ). An active space comprising ten electrons in nine orbitals [i.e., $\mathrm{CAS}(10,9)$ ] and the standard correlation-consistent cc-pVTZ Dunning's basis set ${ }^{27}$ were applied in all calculations. Results obtained in paper I (Ref. 24) showed that this ab initio level was accurate enough, and the computer time was also reasonable to compute a large number of points for both reaction channels. The dynamical correlation energy was included by performing second-order perturbation theory calculations (CASPT2) over the CASSCF wave function using the G2 variant. ${ }^{28}$ All calculations were carried out by means of the MOLCAS 4.1 program. ${ }^{29}$

The analytical representations of the PESs are based on a many-body expansion ${ }^{30}$ for the $\mathrm{NN}^{\prime} \mathrm{O}$ system. In both cases this expansion can be written as

$$
\begin{aligned}
V\left(R_{1}, R_{2}, R_{3}\right)= & V_{\mathrm{NN}^{\prime}}^{(2)}\left(R_{1}\right)+V_{\mathrm{N}^{\prime} \mathrm{O}}^{(2)}\left(R_{2}\right)+V_{\mathrm{NO}}^{(2)}\left(R_{3}\right) \\
& +V_{\mathrm{NN}^{\prime} \mathrm{O}}^{(3)}\left(R_{1}, R_{2}, R_{3}\right),
\end{aligned}
$$

where $V^{(2)}$ and $V^{(3)}$ are the two- and three-body terms, respectively, and $R_{1}, R_{2}$, and $R_{3}$ are the $\mathrm{NN}^{\prime}, \mathrm{N}^{\prime} \mathrm{O}$, and $\mathrm{NO}$ distances, respectively. The one-body $V^{(1)}$ terms have been omitted here because all the diatomic molecules dissociate into atoms in their ground electronic states $\left[\mathrm{N}\left({ }^{4} S\right)\right.$ $\left.+\mathrm{N}^{\prime}\left({ }^{4} S\right)+\mathrm{O}\left({ }^{3} P\right)\right]$. The two-body terms (diatomic potential energy curves) have been fitted using an extended-Rydberg potential up to third or fifth-order, 
TABLE II. Optimal parameters for the ${ }^{3} A^{\prime \prime}$ and ${ }^{3} A^{\prime}$ analytical PESs.

\begin{tabular}{|c|c|c|c|c|c|c|c|c|}
\hline \multicolumn{9}{|c|}{ Two-body terms ${ }^{\mathrm{a}}$} \\
\hline \multirow{2}{*}{\multicolumn{2}{|c|}{$\mathrm{NO}\left(X^{2} \Pi\right)^{\mathrm{b}}$}} & \multicolumn{2}{|c|}{4.3205} & 1.6392 & \multicolumn{2}{|c|}{1.4946} & & \\
\hline & & \multicolumn{2}{|c|}{6.1958} & 11.1408 & \multicolumn{2}{|c|}{9.2570} & 6.9823 & 19.6021 \\
\hline \multirow{2}{*}{\multicolumn{2}{|c|}{$\mathrm{N}_{2}\left(X^{1} \Sigma_{g}^{+}\right)^{\mathrm{b}}$}} & \multirow{2}{*}{\multicolumn{2}{|c|}{$\begin{array}{l}5.2376 \\
3.7790\end{array}$}} & 6.3901 & \multicolumn{2}{|c|}{6.3676} & & \\
\hline & & & & -0.2694 & -0.611 & & -1.9853 & 0.8992 \\
\hline \multicolumn{2}{|c|}{$\begin{array}{c}\text { Three-body term } \\
{ }^{c} A^{\prime \prime}\end{array}$} & \multicolumn{2}{|l|}{${ }^{3} A^{\prime}$} & ${ }^{3} A^{\prime \prime}$ & \multicolumn{2}{|l|}{${ }^{3} A^{\prime}$} & ${ }^{3} A^{\prime \prime}$ & ${ }^{3} A^{\prime}$ \\
\hline$c_{000}$ & 7.4166 & 4.6391 & $c_{040}$ & -21.3448 & -0.3493 & $c_{330}$ & -9.0038 & -4.3822 \\
\hline$c_{100}$ & 6.2889 & -0.4166 & $c_{022}$ & -85.2948 & -13.3716 & $c_{312}$ & 14.2243 & 6.8153 \\
\hline$c_{010}$ & -0.7505 & -2.2228 & $c_{004}$ & -3.0718 & -7.5467 & $c_{240}$ & 7.2399 & 2.1739 \\
\hline$c_{200}$ & 14.4281 & 6.7267 & $c_{500}$ & 8.9826 & 4.7293 & $c_{222}$ & -47.4708 & -26.2565 \\
\hline$c_{110}$ & -8.2247 & -4.4265 & $c_{410}$ & -15.3167 & -16.2801 & $c_{204}$ & 11.6069 & 8.0923 \\
\hline$c_{020}$ & 12.8055 & 3.5126 & $c_{320}$ & 45.2012 & 19.8618 & $c_{150}$ & 4.3132 & -1.8714 \\
\hline$c_{002}$ & -8.4511 & 3.1430 & $c_{302}$ & -23.2229 & -15.1099 & $c_{132}$ & 45.2050 & 19.3009 \\
\hline$c_{300}$ & 13.4837 & 4.7954 & $c_{230}$ & -31.3627 & -11.8867 & $c_{114}$ & 7.7826 & 4.2956 \\
\hline$c_{210}$ & -38.7067 & -9.4334 & $c_{212}$ & 74.0436 & 44.9758 & $c_{060}$ & -0.1399 & -0.1853 \\
\hline$c_{120}$ & 32.9097 & 4.8414 & $c_{140}$ & -12.7283 & 4.6653 & $c_{042}$ & -5.4665 & -2.1531 \\
\hline$c_{102}$ & -30.9122 & 6.0499 & $c_{122}$ & -150.0063 & -43.1208 & $c_{024}$ & -23.4852 & -11.7849 \\
\hline$c_{030}$ & 12.9529 & -3.2647 & $c_{104}$ & 13.6449 & -9.8957 & $c_{006}$ & -3.8063 & -0.1736 \\
\hline$c_{012}$ & 12.7846 & -3.9775 & $c_{050}$ & 5.4116 & -0.0326 & & & \\
\hline$c_{400}$ & 14.8181 & 4.9946 & $c_{032}$ & 69.8672 & 19.0150 & $\gamma_{1}$ & 2.5067 & 2.3806 \\
\hline$c_{310}$ & -48.1654 & -12.3015 & $c_{014}$ & 41.4556 & 20.2721 & $\gamma_{2}$ & 3.0405 & 2.1632 \\
\hline$c_{220}$ & 71.4660 & 13.4089 & $c_{600}$ & 1.8306 & 1.0226 & & & \\
\hline$c_{202}$ & -34.5457 & -18.0314 & $c_{510}$ & -0.3524 & -7.0602 & $R_{1}^{\circ}$ & 2.0980 & 1.9680 \\
\hline$c_{130}$ & -7.0240 & -11.3859 & $c_{420}$ & 3.0192 & 8.6305 & $R_{2}^{\circ}$ & 1.3231 & 1.4789 \\
\hline$c_{112}$ & 74.1564 & 19.3841 & $c_{402}$ & -12.2485 & 0.3747 & $R_{3}^{\circ}$ & 1.3231 & 1.4789 \\
\hline
\end{tabular}

${ }^{a}$ The dissociation energies and the equilibrium distances used in the fits are given in Table III. ${ }^{b}$ Extended Rydberg coefficients used for the ${ }^{3} A^{\prime \prime}$ PES (first row) and the ${ }^{3} A^{\prime}$ PES (second row). cUnits are $c_{i j k}\left(\mathrm{eV} \AA^{-(i+j+k)}\right), \gamma_{i}\left(\AA^{-1}\right), R_{i}^{\circ}(\AA)$, and $a_{i}\left(\AA^{-i}\right)$, where $R_{1}=R_{\mathrm{NN}^{\prime}}, R_{2}=R_{\mathrm{N}^{\prime} \mathrm{O}}$, and $R_{3}=R_{\mathrm{NO}}$.

$$
V^{(2)}(R)=-D_{e}\left(1+\sum_{i=1}^{n \leqslant 5} a_{i} \rho^{i}\right) e^{-a_{1} \rho},
$$

where $D_{e}$ and $R_{e}$ are the equilibrium dissociation energy and the equilibrium bond distance of each diatomic molecule, respectively, and $\rho$ is defined as being equal to $R-R_{e}$.

The three-body term is a product of a sixth-order polynomial $P\left(S_{1}, S_{2}, S_{3}\right)$ and a range function $T\left(S_{1}, S_{2}, S_{3}\right)$, both expressed in terms of symmetry-adapted coordinates $\left(S_{1}, S_{2}, S_{3}\right)$ :

$$
V_{\mathrm{NN}^{\prime} \mathrm{O}}^{(3)}\left(S_{1}, S_{2}, S_{3}\right)=P\left(S_{1}, S_{2}, S_{3}\right) T\left(S_{1}, S_{2}, S_{3}\right),
$$

with

$$
P\left(S_{1}, S_{2}, S_{3}\right)=\sum_{i, j, k=0}^{0 \leqslant i+j+k \leqslant 6} c_{i j k} S_{1}^{i} S_{2}^{j} S_{3}^{k},
$$

with $i, j$, and $k$ being positive integer numbers and

$$
T\left(S_{1}, S_{2}, S_{3}\right)=\prod_{i=1}^{3}\left[1-\tanh \left(\frac{\gamma_{i} S_{i}}{2}\right)\right] .
$$

The range function vanishes the three-body term whenever one of the three atoms is separated from the other two. The symmetry-adapted coordinates used were

$$
S_{1}=\rho_{1},
$$

$$
\begin{aligned}
& S_{2}=\frac{1}{\sqrt{2}}\left(\rho_{2}+\rho_{3}\right), \\
& S_{3}=\frac{1}{\sqrt{2}}\left(\rho_{2}-\rho_{3}\right),
\end{aligned}
$$

and $\rho_{i}=R_{i}-R_{i}^{\circ}$ with $\left(R_{1}^{\circ}, R_{2}^{\circ}, R_{3}^{\circ}\right)$ defining a reference $C_{2 v}$ structure. The use of these coordinates guarantees the permutational $\mathrm{NN}^{\prime}$ symmetry of the analytical PESs.

The two-body parameters $\left(a_{i}\right)$ were optimized by means of a nonlinear least-squares procedure, ${ }^{31}$ while the threebody parameters $\left(c_{i j k}\right.$ and $\left.\gamma_{i}\right)$ were optimized by a weighted nonlinear least-squares method. ${ }^{32}$ In both cases we follow a similar strategy as in our previous works [e.g., $\mathrm{N}\left({ }^{2} D\right)+\mathrm{NO}$ (Ref. 33). $\mathrm{N}\left({ }^{2} D\right)+\mathrm{O}_{2}$ (Ref. 34), or $\mathrm{N}\left({ }^{4} S\right)+\mathrm{O}_{2}$ (Ref. 35)].

\section{B. Analytical representation of the ${ }^{3} A^{\prime \prime}$ PES}

A total of $30 a b$ initio points [CASPT2(10,9) G2/ccpVTZ] calculated for each diatomic molecule (supermolecule calculations for $\mathrm{NO}$ and $\mathrm{N}_{2}$ ) have been fitted by using an extended-Rydberg potential curve [Eq. (4)] up to third order for the two diatomic curves used in the ${ }^{3} A^{\prime \prime}$ PES and up to fifth-order for the ${ }^{3} A^{\prime}$ PES. The spectroscopic $R_{e}$ and $D_{e}$ values $^{36}$ were used for both curves. The final root-meansquare deviation (RMSD) of the fit in each diatomic energy curve was below $0.8 \mathrm{kcal} / \mathrm{mol}$ (with three parameters) and $0.4 \mathrm{kcal} / \mathrm{mol}$ (with five parameters) for both molecules. The 


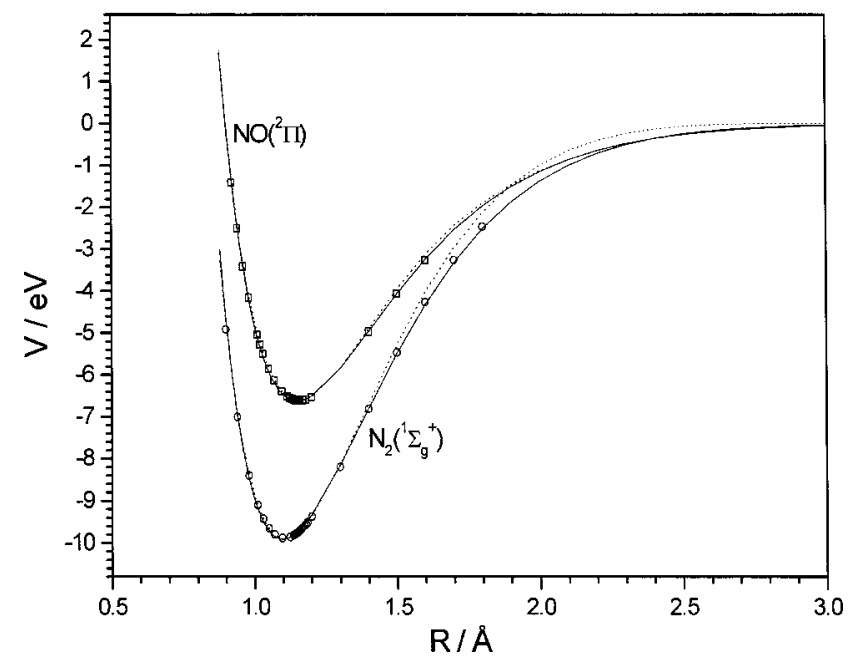

FIG. 1. Ab initio [CASPT2(10,9) G2/cc-pVTZ] diatomic points for the $\mathrm{NO}\left(X^{2} \Pi\right)$ and the $\mathrm{N}_{2}\left(X^{1} \Sigma_{g}^{+}\right)$molecules. The lines show the analytical fit which reproduces also the experimental $R_{e}$ and $D_{e}$, by using a third-order extended-Rydberg potential (dotted lines, for the ${ }^{3} A^{\prime \prime}$ PES) or by using a fifth-order extended-Rydberg potential (solid lines, for the ${ }^{3} A^{\prime}$ PES).

optimal parameters are shown in Table II. Although both curves for each molecule are similar (Fig. 1), it was necessary improve the first diatomic fit (with three parameters), because the small differences at long distances (mainly for $\mathrm{N}_{2}$ ) were significant to remove spurious minima during the fit of the second PES $\left({ }^{3} A^{\prime}\right)$. The spectroscopic constants of the diatomic molecules derived from the optimal analytical curves are summarized in Table III, which compared very well with the experimental data, only with small differences for both analytical curves.

A total of $5630 a b$ initio points [CASPT2 $(10,9)$ G2/ cc-pVTZ] have been computed in different regions of the ${ }^{3} A^{\prime \prime}$ PES to be used in the analytical fit, as summarized below:

(a) 3917 points for the $\mathrm{NN}^{\prime} \mathrm{O}$ region $\left(\mathrm{N}^{\prime}\right.$-abstraction channel) distributed within the following grids:

$$
\begin{aligned}
100^{\circ} \leqslant & \angle \mathrm{NN}^{\prime} \mathrm{O} \leqslant 140^{\circ} \text { for } 0.9 \AA \leqslant R_{\mathrm{NN}^{\prime}} \leqslant 4.5 \AA \\
& \text { and } 0.9 \AA \leqslant R_{\mathrm{N}^{\prime} \mathrm{O}} \leqslant 4.5 \AA \\
& \text { (general and } \mathrm{MEP} \text { ), }
\end{aligned}
$$

$$
\begin{aligned}
80^{\circ} \leqslant & \angle \mathrm{NN}^{\prime} \mathrm{O} \leqslant 180^{\circ} \text { for } 2.1 \AA \leqslant R_{\mathrm{NN}^{\prime}} \leqslant 4.5 \AA \\
& \text { and } 1.0 \AA \leqslant R_{\mathrm{N}^{\prime} \mathrm{O}} \leqslant 1.25 \AA \\
& \text { (entrance valley), } \\
80^{\circ} \leqslant & \angle \mathrm{NN}^{\prime} \mathrm{O} \leqslant 180^{\circ} \text { for } 0.9 \AA \leqslant R_{\mathrm{NN}^{\prime}} 1.2 \AA \\
& \text { and } 1.8 \AA \leqslant R_{\mathrm{N}^{\prime} \mathrm{O}} \leqslant 4.5 \AA \text { (exit valley). }
\end{aligned}
$$

(b) 1713 points for the $\mathrm{NON}^{\prime}$ region (O-abstraction channel) distributed within the following grids:

$$
\begin{aligned}
90^{\circ} \leqslant & \angle \mathrm{NON}^{\prime} \leqslant 180^{\circ} \text { for } 0.9 \AA \leqslant R_{\mathrm{NO}} \leqslant 4.5 \AA \\
& \text { and } 0.9 \AA \leqslant R_{\mathrm{ON}^{\prime}} \leqslant 4.5 \AA \quad \text { (general and MEP), } \\
80^{\circ} \leqslant & \angle \mathrm{NON}^{\prime} \leqslant 150^{\circ} \text { for } 2.3 \AA \leqslant R_{\mathrm{NO}} \leqslant 4.5 \AA \\
& \text { and } 1.0 \AA \leqslant R_{\mathrm{ON}^{\prime}} \leqslant 1.25 \AA \\
& (\text { entrance } \text { or exit valley), } \\
100^{\circ} \leqslant & \angle \mathrm{NON}^{\prime} \leqslant 108^{\circ} \text { for } 1.15 \AA \leqslant R_{\mathrm{NO}} \leqslant 1.6 \AA \\
& \text { and } 1.15 \AA \leqslant R_{\mathrm{ON}^{\prime}} \leqslant 1.6 \AA
\end{aligned}
$$

(MIN1 and TS2 regions).

A small modification was introduced in the ab initio data in order to reproduce as accurately as possible the experimental diatomic dissociation energies and, hence, the exoergicity of reaction (1). As both ab initio values ${ }^{24}$ were smaller than their experimental values, a uniform and first energy shift corresponding to the NO difference was introduced in all the points of the entrance valley (approximately from the line $R_{\mathrm{NO}}<1.8 \AA$ ) for reaction (1) and for all points calculated for reaction (2). Afterward, an additional energy shift was added to the points of the exit valley (approximately from line $R_{\mathrm{NO}}>1.8 \AA$ ) for reaction (1). This procedure was made trying to preserve as much as possible the original $a b$ initio shape of the PES. All these ab initio points along with the first-order partial derivatives with respect to both distances and its angle for MIN1 and TS2 were used in a weighted nonlinear least-squares method ${ }^{32}$ to obtain the optimal fit. The weights used were equal to 1 for almost all points, with the exception of the grids corresponding to the entrance and exit valleys, and also in the first-order partial derivatives, where we used weights between 50 and 100.

TABLE III. Spectroscopic constants of the diatomic molecules.

\begin{tabular}{lccccccc}
\hline \hline \multicolumn{1}{c}{ Molecule } & $R_{e}(\AA)$ & $D_{e}(\mathrm{kcal} / \mathrm{mol})$ & $\omega_{e}\left(\mathrm{~cm}^{-1}\right)$ & $\omega_{e} x_{e}\left(\mathrm{~cm}^{-1}\right)$ & $B_{e}\left(\mathrm{~cm}^{-1}\right)$ & $\alpha_{e}\left(\mathrm{~cm}^{-1}\right)$ & $\bar{D}_{e}\left(\mathrm{~cm}^{-1}\right)$ \\
\hline $\mathrm{NO}\left(\mathrm{X}^{2} \Pi\right)$ & & & & & & & \\
Analytical fit $^{\mathrm{a}}$ & 1.1508 & 152.53 & 1900.4 & 16.348 & 1.6861 & $1.99 \times 10^{-2}$ & $5.40 \times 10^{-6}$ \\
& & & 1947.3 & 16.128 & 1.6861 & $1.60 \times 10^{-2}$ & $5.16 \times 10^{-6}$ \\
Experimental $^{\mathrm{b}}$ & 1.1508 & 152.53 & 1904.2 & 14.075 & 1.6720 & $1.71 \times 10^{-2}$ & $5.47 \times 10^{-6}$ \\
$\mathrm{~N}_{2}\left(X^{1} \Sigma_{g}^{+}\right)$ & & & & & & & \\
Analytical fit $^{\mathrm{a}}$ & 1.0977 & 228.41 & 2374.8 & 15.757 & 1.9754 & $2.15 \times 10^{-2}$ & $5.72 \times 10^{-6}$ \\
& & & 2388.2 & 14.582 & 1.9751 & $1.71 \times 10^{-2}$ & $5.66 \times 10^{-6}$ \\
Experimental $^{\mathrm{b}}$ & 1.0977 & 228.41 & 2358.6 & 14.324 & 1.9982 & $1.73 \times 10^{-2}$ & $5.76 \times 10^{-6}$ \\
\hline \hline
\end{tabular}

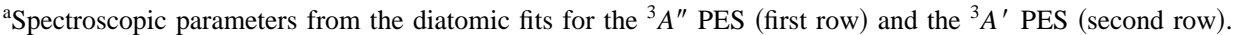

${ }^{b}$ Experimental data of $\mathrm{NO}\left(X^{2} \Pi_{1 / 2}\right)$ and $\mathrm{N}_{2}\left(X^{1} \Sigma_{g}^{+}\right)$from Ref. 36. 

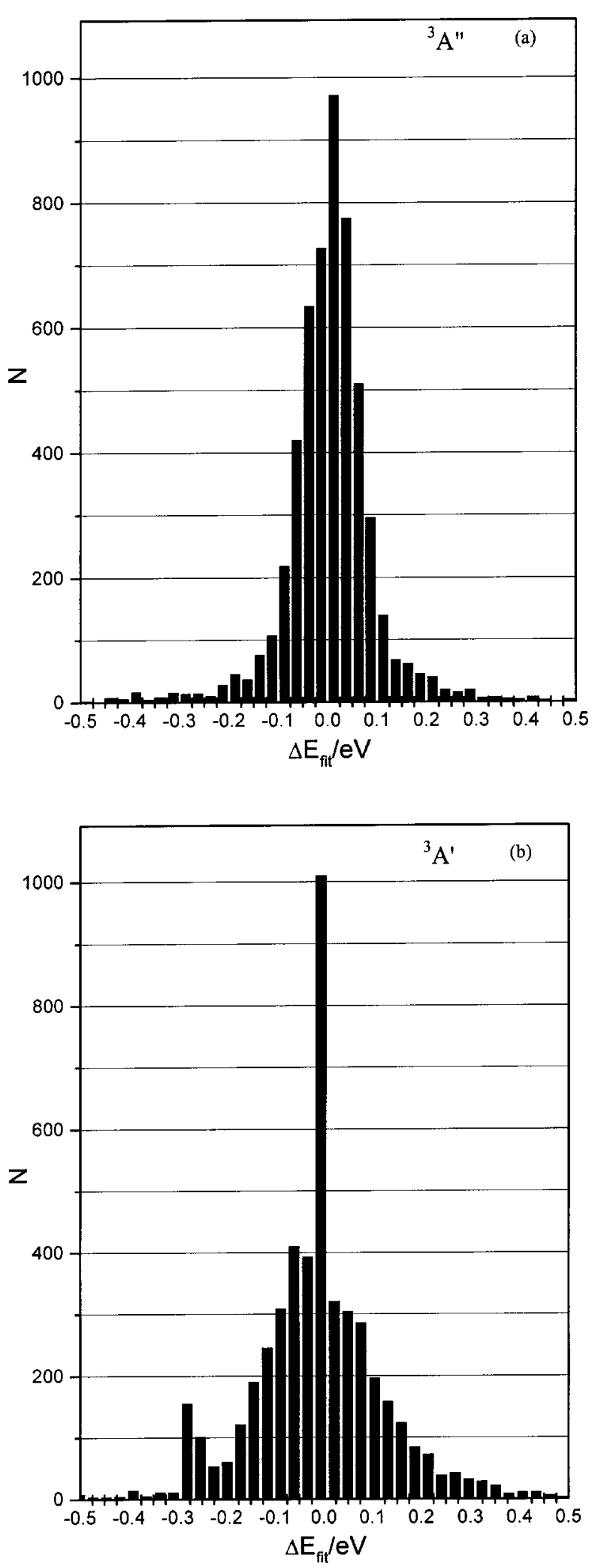

FIG. 2. Distribution of the energy deviations $\left(\Delta E_{\text {fit }}=E_{\text {analytical }}-E_{a b \text { initio }}\right)$ for both analytical PESs: (a) ${ }^{3} A^{\prime \prime}$ (5630 points) and (b) ${ }^{3} A^{\prime}$ (4901 points).

We employed as initial reference structure the $C_{2 v}$ geometry used in our first work $\left(R_{1}^{\circ}=2.17 \AA, R_{2}^{\circ}=R_{3}^{\circ}\right.$ $=1.96 \AA)$ (Ref. 13) and which was slightly optimized by trial and error to improve the final fit. The optimal 55 threebody parameters $\left(c_{i j k}, \gamma_{i}\right.$ and $\left.R_{i}^{\circ}\right)$ are shown in Table II. The final RMSD for the ${ }^{3} A^{\prime \prime}$ surface was equal to $1.44 \mathrm{kcal} / \mathrm{mol}$ for the $\mathrm{NN}^{\prime} \mathrm{O}$ region and $2.59 \mathrm{kcal} / \mathrm{mol}$ for the $\mathrm{NON}^{\prime}$ insertion region. The global RMSD for this surface was 1.80 $\mathrm{kcal} / \mathrm{mol}$. These RMSDs are lower than the estimate errors of the $a b$ initio method, as were shown in paper I (Ref. 24) [e.g., the $a b$ initio $D_{e}(\mathrm{NO})$ value was equal to 146.15 $\mathrm{kcal} / \mathrm{mol}$ compared to the experimental value of 152.53 $\mathrm{kcal} / \mathrm{mol}$. Figure 2(a) shows the energy deviations of the fit (i.e., $\Delta E_{\text {fit }}=E_{\text {analytical }}-E_{a b \text { initio }}$ ), which show a quite narrow distribution supporting the goodness of the fit. On the other hand, the in principle larger RMSD for the $\mathrm{NON}^{\prime}$ region is really much lower in relative terms for this quite repulsive PES region related with the O-abstraction channel. Table IV shows the properties of the stationary points fitted in this region of the PES (TS2 and MIN1), which are located at very high energies over reactants. There is a good agreement between the $a b$ initio properties reported in paper I for these stationary points and the values of the fit shown in Table IV, regardless of the main effort was focused in the fit of the $\mathrm{NN}^{\prime} \mathrm{O}$ region, because reaction (1) was the principal reaction channel due to the absence of energy barrier along the MEP. Thus the fitted TS2 and MIN1 were located only 0.7

$\mathrm{kcal} / \mathrm{mol}(1.7 \%$ of error) and $2.3 \mathrm{kcal} / \mathrm{mol}(6.2 \%$ of error $)$ below their ab initio values, ${ }^{24}$ respectively. Figure 3 presents some equipotential energy curves corresponding to the ${ }^{3} A$ " PES, where it becomes evident the absence of an energy barrier for reaction (1) [see Figs. 3(a) and 3(b)]. In Fig. 3(c) we can observe TS2 and MIN, which are energetically and geometrically very close. This proximity produced some difficulties in their characterization, especially for the harmonic vibrational frequency $\omega_{3}$ (asymmetric stretching of $b_{2}$ symmetry). Several intrinsic reaction coordinate (IRC) calculations were carried out to make sure the MEPs that are schematically shown in Fig. 4(a) for both reaction channels.

\section{Analytical representation of the ${ }^{3} A^{\prime}$ PES}

We have followed for the ${ }^{3} A^{\prime}$ PES the same procedure indicated in previous section for the ${ }^{3} A^{\prime \prime}$ PES. In this case, as was explained before, the diatomic curves were fitted using a fifth-order extended Rydberg (Table II). We used as initial reference structure the optimal geometry found for the ${ }^{3} A^{\prime \prime}$ PES, which was slightly optimized by trial and error.

A total of $4901 a b$ initio points [CASPT2 $(10,9) \mathrm{G} 2 / \mathrm{cc}-$ pVTZ] have been calculated in different regions of the ${ }^{3} A^{\prime}$ PES to be used in the analytical fit, as summarized below:

(a) 2614 points for the $\mathrm{NN}^{\prime} \mathrm{O}$ region $\left(\mathrm{N}^{\prime}\right.$-abstraction channel) distributed within the following grids:

$$
\begin{gathered}
80^{\circ} \leqslant \angle \mathrm{NN}^{\prime} \mathrm{O} \leqslant 180^{\circ} \text { for } 0.9 \AA \leqslant R_{\mathrm{NN}^{\prime}} \leqslant 4.5 \AA \\
\text { and } 0.9 \AA \leqslant R_{\mathrm{N}^{\prime} \mathrm{O}} \leqslant 4.5 \AA \text { (general and MEP), } \\
112^{\circ} \leqslant \angle \mathrm{NN}^{\prime} \mathrm{O} \leqslant 117^{\circ} \text { for } 1.9 \AA \leqslant R_{\mathrm{NN}^{\prime}} \leqslant 2.05 \AA \\
\text { and } 1.14 \AA \leqslant R_{\mathrm{N}^{\prime} \mathrm{O}} \leqslant 1.18 \AA \text { (TS1 region). }
\end{gathered}
$$

(b) 2287 points for the $\mathrm{NON}^{\prime}$ region (O-abstraction channel) following the ranges:

$$
\begin{aligned}
& 90^{\circ} \leqslant \angle \mathrm{NON}^{\prime} \leqslant 180^{\circ} \text { for } 0.9 \AA \leqslant R_{\mathrm{NO}} \leqslant 4.5 \AA \\
& \text { and } 0.9 \AA \leqslant R_{\mathrm{ON}^{\prime}} \leqslant 4.5 \AA \text { (general and MEP), }
\end{aligned}
$$


TABLE IV. Properties of the stationary points located on the ${ }^{3} A^{\prime \prime}$ and ${ }^{3} A^{\prime}$ analytical PESs.

\begin{tabular}{|c|c|c|c|c|c|c|c|}
\hline $\begin{array}{l}\text { Stationary } \\
\text { points }\end{array}$ & $\begin{array}{l}R_{e(\mathrm{NO})}(\AA)^{\mathrm{a}} \\
R_{e\left(\mathrm{NN}^{\prime}\right)}(\AA)\end{array}$ & $R_{c\left(\mathrm{~N}^{\prime} \mathrm{O}\right)}(\AA)$ & $\begin{array}{l}<\mathrm{NON}^{\prime}(\mathrm{deg})^{\mathrm{a}} \\
<\mathrm{NN}^{\prime} \mathrm{O}(\mathrm{deg})\end{array}$ & & $\omega_{i}\left(\mathrm{~cm}^{-1}\right)^{\mathrm{b}}$ & & $\Delta E\left(\mathrm{kcal} \mathrm{mol}^{-1}\right)$ \\
\hline \multicolumn{8}{|l|}{${ }^{3} A^{\prime \prime}$ PES } \\
\hline $\mathrm{TS} 2$ & 1.3965 & 1.2609 & 102.01 & 299.22 & 1299.14 & $374.71 \mathrm{i}$ & $40.45(40.02)$ \\
\hline MIN1 & 1.3218 & 1.3218 & 97.13 & 375.39 & 1274.70 & $41.54^{\mathrm{d}}$ & $39.25(38.95)$ \\
\hline \multicolumn{8}{|l|}{${ }^{3} A^{\prime}$ PES } \\
\hline TS2 & 1.6892 & 1.2008 & 115.01 & 445.72 & 1542.79 & $609.78 \mathrm{i}$ & $27.33(27.45)$ \\
\hline MIN1 & 1.2921 & 1.2921 & 114.13 & 530.96 & 1105.97 & 1234.42 & 13.87 (15.19) \\
\hline TS1 & 1.9755 & 1.1571 & 115.21 & 428.07 & 1793.61 & $380.27 \mathrm{i}$ & $8.35(8.74)$ \\
\hline $\mathrm{TS} 1^{\mathrm{e}}$ & 1.8913 & 1.1690 & 116.5 & 438 & 1648 & $544 \mathrm{i}$ & $14.4(14.7)$ \\
\hline
\end{tabular}

${ }^{a}$ Variables used for the $\mathrm{NON}^{\prime}$ structures: (top) TS2, MIN1, and for the $\mathrm{NN}^{\prime} \mathrm{O}$ structures. (bottom) TS1.

${ }^{b}$ Harmonic vibrational frequencies: (a) $\mathrm{NON}^{\prime}-\mathrm{C}_{\mathrm{s}}: \omega_{1}$ ( $\mathrm{NON}^{\prime}$ bend., $\left.\mathrm{a}^{\prime}\right), \omega_{2}\left(\mathrm{ON}^{\prime}\right.$ str., $\left.\mathrm{a}^{\prime}\right), \omega_{3}$ (NO str., $\left.\mathrm{a}^{\prime}\right)$ respectively; (b) $\mathrm{NON}^{\prime}-C_{2 v}: \omega_{1}$ (NON' bend., $\mathrm{a}_{1}$ ), $\omega_{2}$ (sym. str., $\mathrm{a}_{1}$ ), $\omega_{3}$ (asym. str., $\mathrm{b}_{2}$ ), respectively (YZ taken as the molecular plane); (c) $\mathrm{NN}^{\prime} \mathrm{O}-\mathrm{C}_{\mathrm{s}}: \omega_{1}\left(\mathrm{NN}^{\prime} \mathrm{O}\right.$ bend., $\left.\mathrm{a}^{\prime}\right), \omega_{2}\left(\mathrm{~N}^{\prime} \mathrm{O}\right.$ str., $\left.\mathrm{a}^{\prime}\right)$, and $\omega_{3}\left(\mathrm{NN}^{\prime}\right.$ str., $\left.\mathrm{a}^{\prime}\right)$, respectively. Masses of the most abundant isotopes were used. ${ }^{14} \mathrm{~N}$ and ${ }^{16} \mathrm{O}$.

${ }^{c}$ Energy respect to $\mathrm{N}\left({ }^{4} S\right)+\mathrm{N}^{\prime} \mathrm{O}$. The value corrected with the difference of zero point energies is shown in parentheses.

${ }^{\mathrm{d}}$ This frequency has an estimated error of $\pm 100 \%$ due to its difficult numerical characterization (very flat surface).

${ }^{e}$ Properties of a previous analytical fit (Ref. 20).

$$
\begin{gathered}
121^{\circ} \leqslant \angle \mathrm{NON}^{\prime} \leqslant 127^{\circ} \text { for } 1.1 \AA \leqslant R_{\mathrm{NO}} \leqslant 1.35 \AA \\
\text { and } 1.25 \AA \leqslant R_{\mathrm{ON}^{\prime}} \leqslant 2.0 \AA
\end{gathered}
$$

(MIN1 and TS2 regions).

Here we used the same correction in the ab initio data as for the ${ }^{3} A^{\prime \prime}$ PES. These $a b$ initio points with weight equal to 1 (excepting the grid around TS1 that has a weight of 1000), together with the first-order partial derivatives with respect to the internal coordinates of TS1, MIN1, and TS2 with weight 100 , were used in the weighted nonlinear leastsquares method to obtain the optimal analytical fit. The final RMSD for the ${ }^{3} A^{\prime}$ surface was the following: 1.61 $\mathrm{kcal} / \mathrm{mol}$ for the $\mathrm{NN}^{\prime} \mathrm{O}$ region and $2.85 \mathrm{kcal} / \mathrm{mol}$ for the $\mathrm{NON}^{\prime}$ region, with a global RMSD of $2.28 \mathrm{kcal} / \mathrm{mol}$. Figure 2(b) shows the distribution of deviations for this fit, which is somewhat poorer than that for the ${ }^{3} A$ " PES. Figure 5 shows some equipotential curves corresponding to the ${ }^{3} A^{\prime}$ PES, where is possible to see the transition state TS1 [Figs. 5(a) and 5(b)] and TS2 and MIN1 [Fig. 5(c)]. The properties of the different stationary points are depicted in Table IV. The analytical ${ }^{3} A^{\prime}$ PES reproduces very well the $a b$ initio TS1 properties [e.g., to be compared with the ab initio geometry $R_{\mathrm{NN}^{\prime}}=1.9680 \AA, \quad R_{\mathrm{N}^{\prime} \mathrm{O}}=1.1578 \AA, \quad \angle \mathrm{NN}^{\prime} \mathrm{O}=116.04^{\circ}$, $\Delta E^{\neq}=8.38 \mathrm{kcal} / \mathrm{mol}$ (Ref. 24)] which is the most important stationary point. These results can also be compared with a previous analytical PES (Ref. 20) based on limited ab initio data, which had a larger energy barrier and a longer NN distance (see Table IV). The lowering of the energy barrier was discussed in paper I (Ref. 24) and justified due to the importance of the $\mathrm{N}$ and $\mathrm{O} 2 s$ electron correlation, omitted in early $a b$ initio $^{14}$ studies. Furthermore, the strengthening of the NN distance was also observed in similar studies [e.g., $\mathrm{N}\left({ }^{4} S\right)+\mathrm{O}_{2}$ (Ref. 37)], when the geometry optimization was carried out directly by including the dynamical correlation energy. ${ }^{24}$

The quality of this PES fit is a bit worse for the TS2 and MIN1 structures. Nevertheless, the errors in their fitted ener- gies were lower than a $2 \%$ of the corresponding ab initio values. Figure 4(b) presents schematically the MEPs corresponding to both reaction channels. It can be observed by comparison with the MEPs of the ${ }^{3} A^{\prime \prime}$ PES that the second reaction channel becomes more accessible than for the ${ }^{3} A^{\prime \prime}$ PES, although still at high temperatures.

\section{VARIATIONAL TRANSITION-STATE THERMAL RATE CONSTANTS}

Thermal rate constants for both reaction channels of $\mathrm{N}\left({ }^{4} S\right)+\mathrm{NO}\left(X^{2} \Pi\right)$ and also for the reverse reaction have been calculated within the $200-5000 \mathrm{~K}$ and $600-5000 \mathrm{~K}$ temperature intervals, respectively. We have considered different levels of the variational transition-state theory ${ }^{38}$ (VTST), as implemented in the POLYRATE code. ${ }^{39}$ The rate constant values finally presented were the improved canonical (ICVT) ones with a microcanonical optimized multidimensional tunneling correction ( $\mu \mathrm{OMT})$ for reaction (1) and its reverse and the ICVT ones with a small curvature tunneling correction (SCT) for the O-abstraction reaction. For this latter reaction this tunnel correction was the only acceptable one, due to the problems generated by the curvature of the MEP, with the presence also of the MIN1 and the two equivalent TS2s.

To calculate the total thermal rate constants for all reactions, we have used the two PESs $\left({ }^{3} A^{\prime \prime}\right.$ and $\left.{ }^{3} A^{\prime}\right)$ that can contribute to reactivity within the temperature range studied. Moreover, we have also considered a spin-orbit correction as in recent similar studies, ${ }^{33,35}$ to take into account the two NO reactant spin-orbit states for reactions (1) and (2). Thus, the electronic partition function $[Q(T)]$ of $\mathrm{NO}\left(X^{2} \Pi\right)$ is given by

$$
Q_{\mathrm{NO}\left({ }^{2} \Pi\right)}^{\text {elec }}(T)=g\left({ }^{2} \Pi_{1 / 2}\right)+g\left({ }^{2} \Pi_{3 / 2}\right) e^{-\Delta / R T},
$$

where $g\left({ }^{2} \Pi_{1 / 2}\right)$ and $g\left({ }^{2} \Pi_{3 / 2}\right)$ are both equal to 2 , and the 

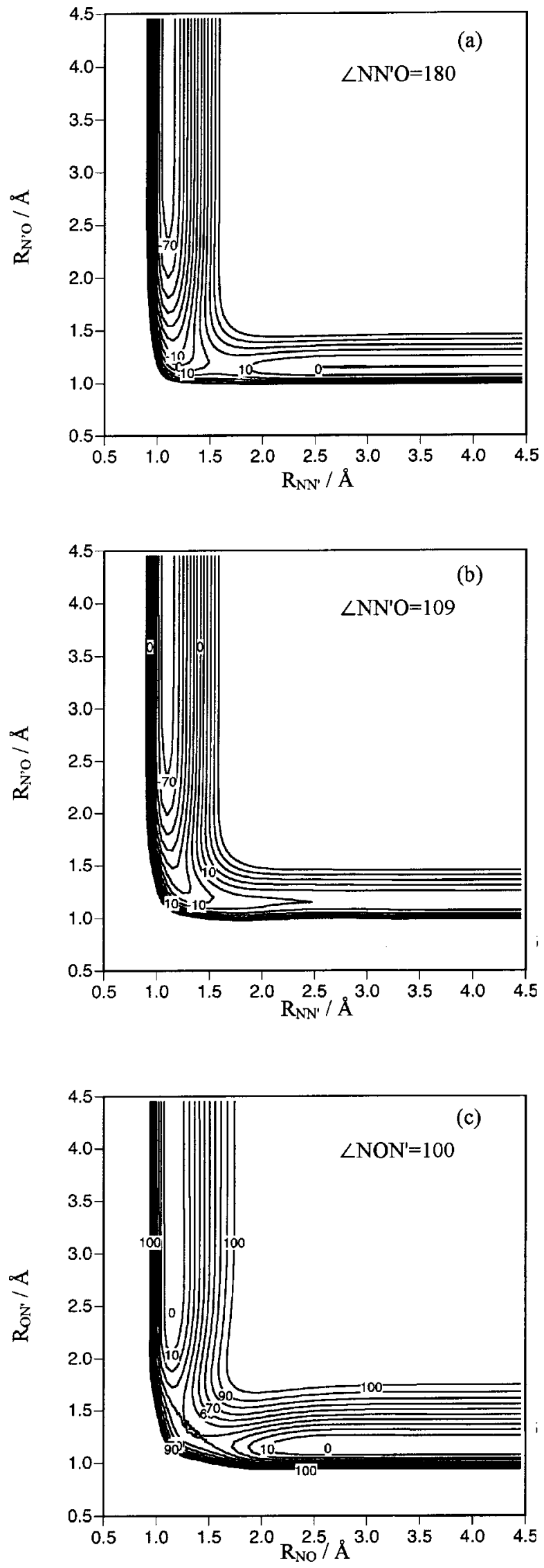

FIG. 3. Equipotential energy contour diagrams of the ${ }^{3} A^{\prime \prime}$ analytical PES for $C_{\infty v}$ (a), $C_{s}$ (b), and $C_{2 v}$ (c) geometries. The contours are depicted in increments of $10 \mathrm{kcal} / \mathrm{mol}$, and the zero of energy is taken in reactants $\left[\mathrm{N}\left({ }^{4} S\right)\right.$ $\left.+\mathrm{N}^{\prime} \mathrm{O}\right]$.
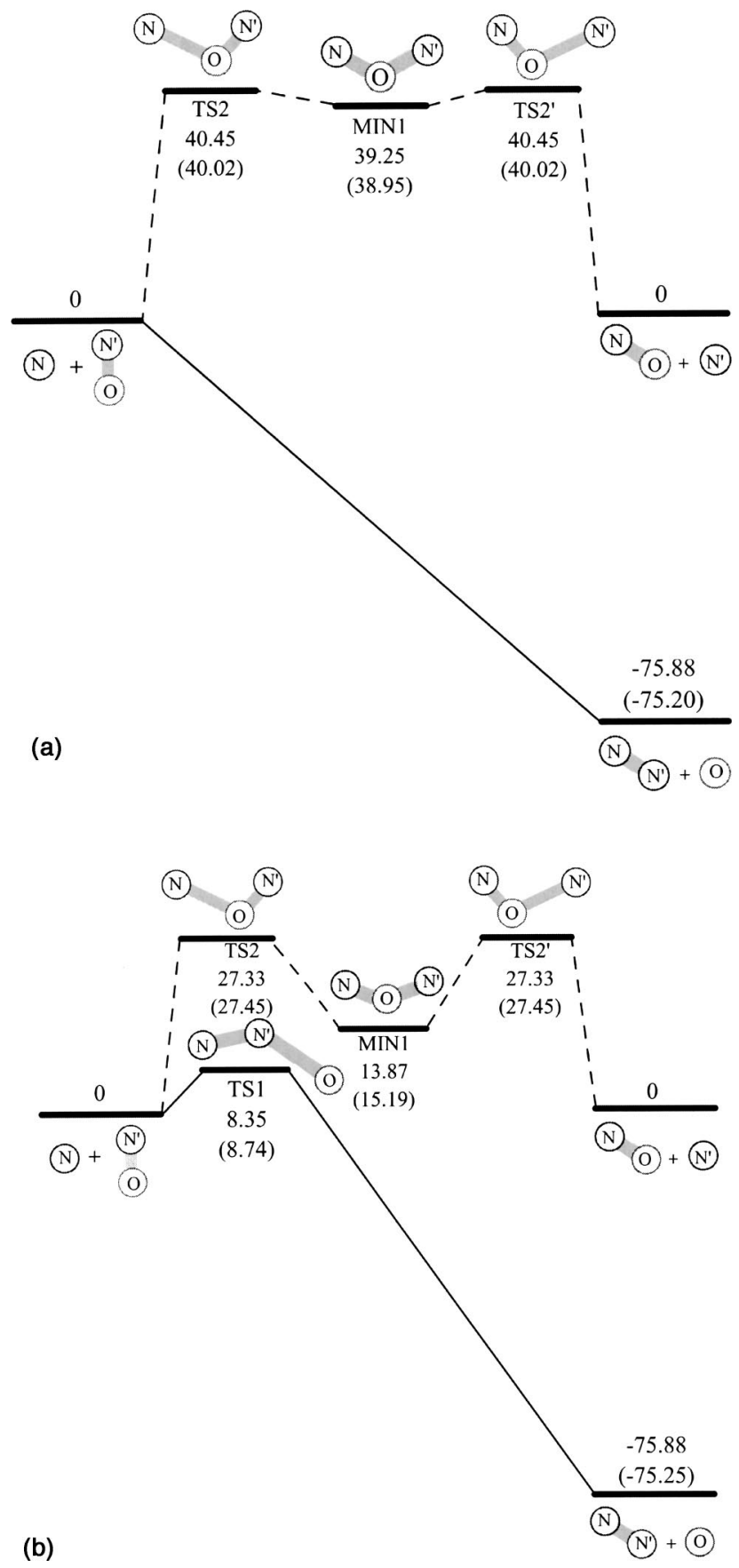

FIG. 4. Schematic representation of the lowest MEP for both the ${ }^{3} A^{\prime \prime}$ (a) and the ${ }^{3} A^{\prime}$ (b) analytical PESs. Energies are given relative to reactants $\left[\mathrm{N}\left({ }^{4} S\right)+\mathrm{NO}\right]$ in $\mathrm{kcal} / \mathrm{mol}$.

spin-orbit splitting $\Delta\left({ }^{2} \Pi_{3 / 2}-{ }^{2} \Pi_{1 / 2}\right)$ is equal to $121.1 \mathrm{~cm}^{-1}$. The expression for $k_{1}$ and $k_{2}$ can be obtained from the equation

$$
k_{i}=k_{i}\left({ }^{3} A^{\prime \prime}\right)+k_{i}\left({ }^{3} A^{\prime}\right)=\frac{3 k_{i}^{\prime}\left({ }^{3} A^{\prime \prime}\right)+3 k_{i}^{\prime}\left({ }^{3} A^{\prime}\right)}{4\left(2+2 e^{-174.2 / T}\right)}, \quad i=1,2 .
$$

Primed $k_{i}$ show the rate constants without the inclusion of the electronic partition functions of reactants and the transition state. 

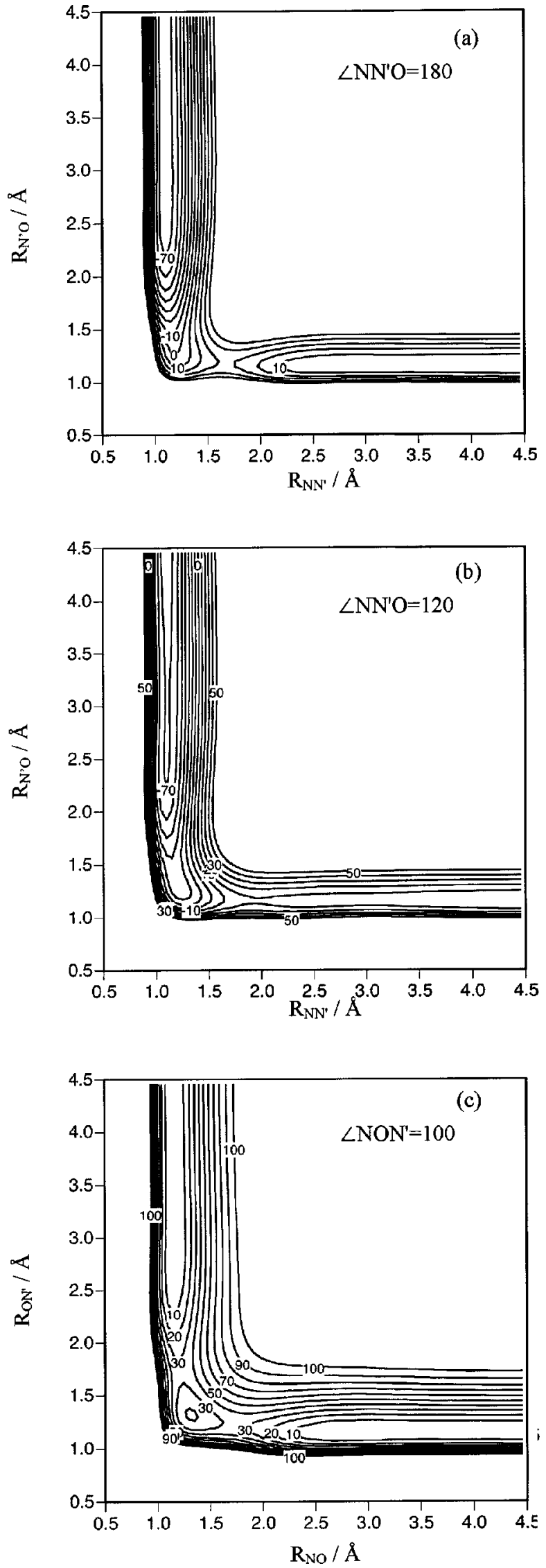

FIG. 5. Equipotential energy contour diagrams of the ${ }^{3} A^{\prime}$ analytical PES for $C_{\infty v}$ (a), $C_{s}$ (b), and $C_{2 v}$ (c) geometries. The contours are depicted in increments of $10 \mathrm{kcal} / \mathrm{mol}$, and the zero of energy is taken in reactants $\left[\mathrm{N}\left({ }^{4} S\right)\right.$ $\left.+\mathrm{N}^{\prime} \mathrm{O}\right]$.
Due to the presence of a minimum (MIN1) in the MEP for reaction (2) (Fig. 4), we have considered the following microscopic mechanism to determine its rate constant $\left(k_{2}\right)$ :

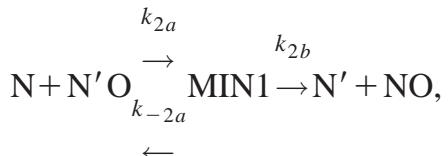

which is more properly applied to the ${ }^{3} A^{\prime}$ PES, which presents a more stable minimum and which as well will produce the most important contribution to the total $k_{2}$. The application of the steady-state assumption to this type of mechanism ${ }^{40}$ will give place to the velocity equation

$$
v=\frac{\mathrm{d}[\mathrm{NO}]}{\mathrm{d} t}=\frac{k_{2 a} k_{2 b}}{k_{-2 a}+k_{2 b}}[\mathrm{~N}]\left[\mathrm{N}^{\prime} \mathrm{O}\right]=k_{2}[\mathrm{~N}]\left[\mathrm{N}^{\prime} \mathrm{O}\right] .
$$

Due to $k_{2 b}=k_{-2 a}$, the final rate constant $k_{2}$ becomes equal to $k_{2 a} / 2$. Hence VTST calculations determined firstly $k_{2 a}$ for each PES before calculating the total $k_{2}$. The steady-state approximation is valid for $k_{2 a} \ll\left(k_{-2 a}+k_{2 b}\right)=2 k_{2 b} \cdot{ }^{40} \mathrm{We}$ have checked that this condition always fulfills in the present case (e.g., for the ${ }^{3} A^{\prime}$ PES, $k_{2 b} / k_{2 a}>10^{11}$ for all temperatures).

For the reverse reaction $(-1)$, we have also considered the corresponding oxygen atom spin-orbit states $\left({ }^{3} P_{2},{ }^{3} P_{1}\right.$, and ${ }^{3} P_{0}$ ). Thus its electronic partition function is

$$
Q_{\mathrm{O}\left({ }^{3} P\right)}^{\text {elec }}(T)=g\left({ }^{3} P_{2}\right)+g\left({ }^{3} P_{1}\right) e^{-\Delta_{1} / R T}+g\left({ }^{3} P_{0}\right) e^{-\Delta_{0} / R T},
$$

where $g(i)$ represents the electronic degeneracy of each $i$ spin-orbit state, which are equal to 5, 3, and 1, respectively, and $\Delta_{i}$ are the energetic differences between the corresponding $i$ excited electronic state and the ground electronic state, $\Delta_{1}\left({ }^{3} P_{1}-{ }^{3} P_{2}\right)$ and $\Delta_{2}\left({ }^{3} P_{0}-{ }^{3} P_{2}\right)$, which are equal to 158.27 and $226.98 \mathrm{~cm}^{-1}$, respectively. ${ }^{1}$ Therefore, $k_{-1}$ can be determined by the equation

$$
\begin{aligned}
k_{-1} & =k_{-1}\left({ }^{3} A^{\prime \prime}\right)+k_{-1}\left({ }^{3} A^{\prime}\right) \\
& =\frac{3 k_{-1}^{\prime}\left({ }^{3} A^{\prime \prime}\right)+3 k_{-1}^{\prime}\left({ }^{3} A^{\prime}\right)}{\left(5+3 e^{-227.7 / T}+e^{-326.6 / T}\right)} .
\end{aligned}
$$

Table V shows the calculated VTST rate constants for reaction (1) using the present and previous PESs, comparing also with available experimental data. As was shown in paper I ${ }^{24}$ the estimated complete basis set limit for the energy barrier (TS1) in ${ }^{3} A^{\prime}$ PES is $6.74 \mathrm{kcal} / \mathrm{mol}$. Thus a simple scale factor was introduced in the VTST calculations for this PES to better account for this value, instead of the value reproduced by the analytical PES $(8.35 . \mathrm{kcal} / \mathrm{mol})$. The agreement with the experimental data when considering the new PESs is very good at low and also at very high temperatures. Previous PESs produce poorer rate constants (see Table V), lower by a $10-15$ factor at low temperatures and by a $1.2-$ 2.5 factor at high temperatures $(T>1500 \mathrm{~K})$. Comparing the rate constants arising from each PES, it is appreciated that the effect of the ${ }^{3} A^{\prime}$ is certainly minor. The contribution of this latter PES to the total rate constant is small even at high temperatures (e.g., only $10.8 \%$ at $2500 \mathrm{~K}$ ). Therefore, the influence of the inclusion of the scaled barrier is very small. 
TABLE V. Theoretical ICVT/ $\mu$ OMT and experimental thermal rate constants for the $\mathrm{N}\left({ }^{4} S\right)+\mathrm{NO}\left(X^{2} \Pi\right) \rightarrow \mathrm{O}\left({ }^{3} P\right)+\mathrm{N}_{2}\left(X^{1} \Sigma_{g}^{+}\right)$reaction. ${ }^{a}$

\begin{tabular}{|c|c|c|c|c|c|c|c|}
\hline \multirow[b]{2}{*}{$T(\mathrm{~K})$} & \multicolumn{2}{|c|}{$k_{1}\left({ }^{3} A^{\prime \prime}\right)$} & \multicolumn{2}{|c|}{$k_{1}\left({ }^{3} A^{\prime}\right)$} & \multicolumn{3}{|c|}{$k_{1}$} \\
\hline & New PES & Previous PES ${ }^{b}$ & New PES ${ }^{c}$ & Previous PES ${ }^{\mathrm{d}}$ & New PESs ${ }^{\mathrm{e}}$ & Previous PESs ${ }^{\mathrm{e}}$ & Experiment $\mathrm{f}^{\mathrm{f}}$ \\
\hline 200 & $6.52 \times 10^{-11}$ & $2.04 \times 10^{-12}$ & $1.38 \times 10^{-19}$ & $1.17 \times 10^{-26}$ & $6.52 \times 10^{-11}$ & $2.04 \times 10^{-12}$ & $4.89 \times 10^{-11}, 3.46 \times 10^{-11}$ \\
\hline 300 & $4.68 \times 10^{-11}$ & $2.96 \times 10^{-12}$ & $4.20 \times 10^{-17}$ & $7.30 \times 10^{-22}$ & $4.68 \times 10^{-11}$ & $2.96 \times 10^{-12}$ & $3.75 \times 10^{-11}, 2.93 \times 10^{-11}$ \\
\hline 400 & $3.79 \times 10^{-11}$ & $3.79 \times 10^{-12}$ & $7.92 \times 10^{-16}$ & $2.05 \times 10^{-19}$ & $3.79 \times 10^{-11}$ & $3.79 \times 10^{-12}$ & $3.28 \times 10^{-11}, 2.70 \times 10^{-11}$ \\
\hline 500 & $3.39 \times 10^{-11}$ & $4.57 \times 10^{-12}$ & $4.85 \times 10^{-15}$ & $6.39 \times 10^{-18}$ & $3.39 \times 10^{-11}$ & $4.57 \times 10^{-12}$ & \\
\hline 600 & $3.20 \times 10^{-11}$ & $5.34 \times 10^{-12}$ & $1.68 \times 10^{-14}$ & $6.58 \times 10^{-17}$ & $3.20 \times 10^{-11}$ & $5.34 \times 10^{-12}$ & \\
\hline 800 & $3.05 \times 10^{-11}$ & $6.83 \times 10^{-12}$ & $8.40 \times 10^{-14}$ & $1.29 \times 10^{-15}$ & $3.06 \times 10^{-11}$ & $6.83 \times 10^{-12}$ & \\
\hline 1000 & $3.02 \times 10^{-11}$ & $8.31 \times 10^{-12}$ & $2.32 \times 10^{-13}$ & $8.10 \times 10^{-15}$ & $3.05 \times 10^{-11}$ & $8.32 \times 10^{-12}$ & \\
\hline 1250 & $3.01 \times 10^{-11}$ & $1.01 \times 10^{-11}$ & $5.48 \times 10^{-13}$ & $3.71 \times 10^{-14}$ & $3.07 \times 10^{-11}$ & $1.02 \times 10^{-11}$ & $3.77 \times 10^{-11}$ \\
\hline 1500 & $3.01 \times 10^{-11}$ & $1.20 \times 10^{-11}$ & $1.00 \times 10^{-12}$ & $1.06 \times 10^{-13}$ & $3.11 \times 10^{-11}$ & $1.21 \times 10^{-11}$ & $4.19 \times 10^{-11}$ \\
\hline 1750 & $3.03 \times 10^{-11}$ & $1.38 \times 10^{-11}$ & $1.58 \times 10^{-12}$ & $2.28 \times 10^{-13}$ & $3.19 \times 10^{-11}$ & $1.40 \times 10^{-11}$ & $4.52 \times 10^{-11}$ \\
\hline 2000 & $3.07 \times 10^{-11}$ & $1.56 \times 10^{-11}$ & $2.26 \times 10^{-12}$ & $4.17 \times 10^{-13}$ & $3.29 \times 10^{-11}$ & $1.60 \times 10^{-11}$ & $4.78 \times 10^{-11}$ \\
\hline 2500 & $3.18 \times 10^{-11}$ & $1.92 \times 10^{-11}$ & $3.87 \times 10^{-12}$ & $9.99 \times 10^{-13}$ & $3.57 \times 10^{-11}$ & $2.02 \times 10^{-11}$ & $5.18 \times 10^{-11}$ \\
\hline 3000 & $3.33 \times 10^{-11}$ & $2.28 \times 10^{-11}$ & $5.70 \times 10^{-12}$ & $1.85 \times 10^{-12}$ & $3.90 \times 10^{-11}$ & $2.46 \times 10^{-11}$ & $5.46 \times 10^{-11}$ \\
\hline 4000 & $3.67 \times 10^{-11}$ & $3.01 \times 10^{-11}$ & $9.76 \times 10^{-12}$ & $4.25 \times 10^{-12}$ & $4.65 \times 10^{-11}$ & $3.43 \times 10^{-11}$ & $5.83 \times 10^{-11}$ \\
\hline 5000 & $4.06 \times 10^{-11}$ & $3.72 \times 10^{-11}$ & $1.41 \times 10^{-11}$ & $7.36 \times 10^{-12}$ & $5.46 \times 10^{-11}$ & $4.46 \times 10^{-11}$ & $6.06 \times 10^{-11}$ \\
\hline
\end{tabular}

a Rate constants are given in $\mathrm{cm}^{3}$ molecule ${ }^{-1} \mathrm{~s}^{-1}$. Transmission coefficients $\kappa$ are equal to 1 for ${ }^{3} A^{\prime \prime}$ PES.

${ }^{\mathrm{b}} \mathrm{Using}$ the PES of Ref. 15 and including the electronic statistical degeneracy factor.

${ }^{\mathrm{C} I C V T} / \mu \mathrm{OMT}$ rate constants calculated on the ${ }^{3} \mathrm{~A}^{\prime}$ PES with an scaled energy barrier equal to $6.74 \mathrm{kcal} / \mathrm{mol}$ [the ab initio CBS limit (Ref. 24)].

${ }^{\mathrm{d}}$ Using the PES of Ref. 20 and including the electronic statistical degeneracy factor.

${ }^{\mathrm{e}}$ The total theoretical rate constant $k_{1}$ is calculated using Eq. (10) and the data of the columns on the left.

${ }^{f}$ Data from Refs. 3 and $9(200-400 \mathrm{~K})$ and from Ref. 8 (1500-4000 K). Italic numbers show two extrapolated values to allow additional comparison. Errors are indicated in Table I.

For instance, at $2500 \mathrm{~K}$ the value of $k\left({ }^{3} A^{\prime}\right.$, with barrier not scaled) decreases only until $2.83 \times 10^{-12} \mathrm{~cm}^{3}$ molecule $^{-1}$ $\mathrm{s}^{-1}$ (cf. in Table V), which leads to almost the same total rate constant $\left(3.46 \times 10^{-11} \mathrm{~cm}^{3}\right.$ molecule $\left.\mathrm{s}^{-1}\right)$. The key improvement in the new theoretical rate constants arises from the new ${ }^{3} A^{\prime \prime}$ PES, which gives rate constants higher than the previous PES. ${ }^{15}$ In addition, Fig. 6(a) (note the enlarged scale in the $k$ axis) shows the correct change of slope as compared with the experimental data at $\operatorname{low}^{3,9}$ and high temperatures, ${ }^{8}$ not properly described by using previous PESs.

Nevertheless, there are some differences in comparison to another experimental data ${ }^{2,7}$ which do not agree with the recommended experimental data, ${ }^{8,9}$ although all of them are actually within a relatively small range of $k$ values. The behavior observed at low temperatures for reaction (1) due to the ${ }^{3} A^{\prime \prime}$ rate constant is not originated by tunnel effect (in all cases the transmission coefficient $\kappa$ was equal to 1 ), as it should be expected for a barrierless reaction, but to the vibrationally adiabatic effective energy barrier derived from the shape of the MEP at each temperature. A slight contribution to the increase of $k_{1}$ when the temperature decreases is also originated by the temperature dependence of $Q_{\mathrm{NO}\left({ }^{2} \Pi\right)}^{\text {elec }}(T)$. This effect was also reported in a previous study, ${ }^{18}$ where QCT thermal rate constants were calculated with a different analytical ${ }^{3} A^{\prime \prime}$ PES within the $200-1000 \mathrm{~K}$ interval. For these calculations, the introduction of this temperature-dependent statistical degeneracy factor was the only way to produce a positive slope in the Arrhenius plot. Moreover, these QCT rate constants were very similar to the present VTST ones, though for a shorter temperature range. For instance, using their QCT values for the ${ }^{3} A^{\prime \prime}$ PES and Eq. (10) [assuming that $k\left({ }^{3} A^{\prime}\right)$ is negligible for $T$ $<1000 \mathrm{~K}$ ] we obtain the following QCT values at 200, 300, and $1000 \mathrm{~K}: 4.24 \times 10^{-11}, 4.02 \times 10^{-11}$, and $3.61 \times 10^{-11}$ $\mathrm{cm}^{3}$ molecule ${ }^{-1} \mathrm{~s}^{-1}$, respectively (cf. Table V). The major shortcoming of this earlier ${ }^{3} A^{\prime \prime}$ PES is its rather semiempirical character and inability to describe reaction (2).

Table VI presents the VTST rate constants for reaction (2), which are also displayed in Fig. 6(b). A three-parameter Kooij expression for $k_{2}$ was used according to the following equation:

$$
k=A T^{n} e^{B / T},
$$

where $A, n$, and $B$ are parameters to be optimized by means of a least-squares procedure to fit the rate constants, as is given in Fig. 6(b). For this reaction with an important energy barrier, the small effect of the oxygen spin-orbit states is negligible. In this reaction the main contribution to the total rate constant is due to the ${ }^{3} A^{\prime}$ PES, following an opposite behavior as for reaction (1). Although $k_{2}$ values are much lower than the $k_{1}$ values at low and moderate temperatures $(T<1000 \mathrm{~K})$, the present results show that the O-abstraction channel accounts for $3.0 \%$ of the total reaction [the branching ratio $k_{2} /\left(k_{1}+k_{2}\right)$ being expressed in percentage] at 5000 $\mathrm{K}$. This value is equal to the QCT value calculated for the similar reaction but with $\mathrm{N}\left({ }^{2} D\right)$ (Ref. 33) and a much lower temperature $(1500 \mathrm{~K})$. The addition of these values at high temperatures is in good agreement with the qualitative accessible experimental information, which indicates that this branching ratio ranges from $0 \%$ to $20 \%$ when increasing the nitrogen atom translational energy ${ }^{22,23}$ [possibly including also $\mathrm{N}\left({ }^{2} D\right)$ and $\mathrm{N}\left({ }^{2} P\right)$ ]. Although reaction (2) involves heavy atoms, the transmission coefficients $\kappa$ calculated by the SCT method at different temperatures are high even at room temperature (e.g., 2.58 for ${ }^{3} A^{\prime \prime}$ and 1.79 for the ${ }^{3} A^{\prime}$ at $300 \mathrm{~K}$ ) as was also found in similar studies. ${ }^{35,41}$ 


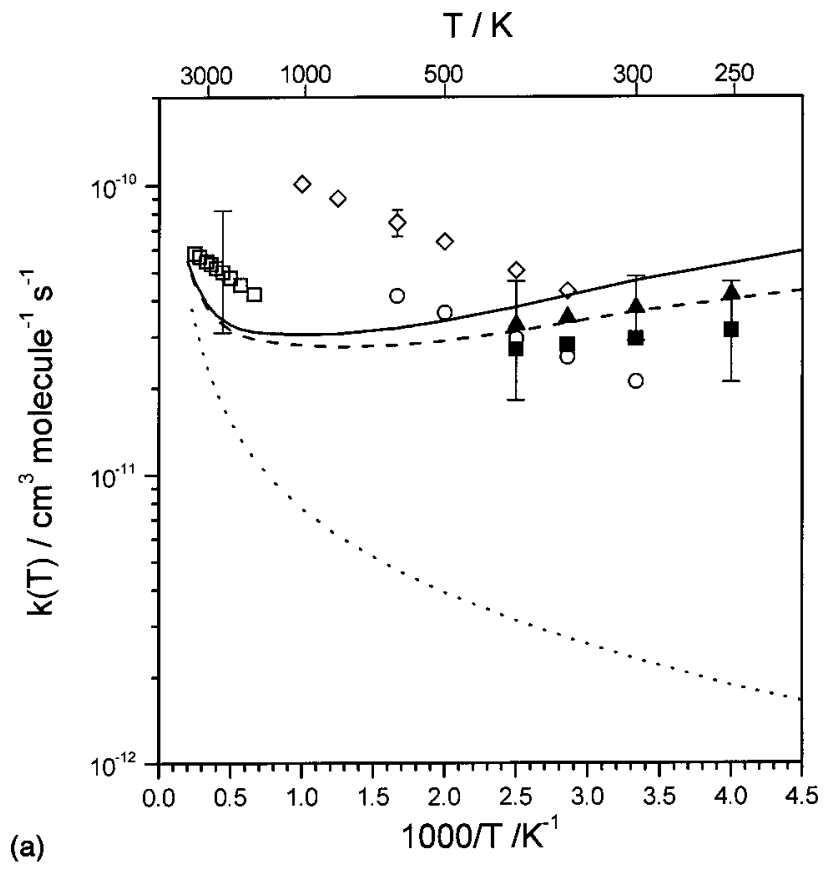

(a)

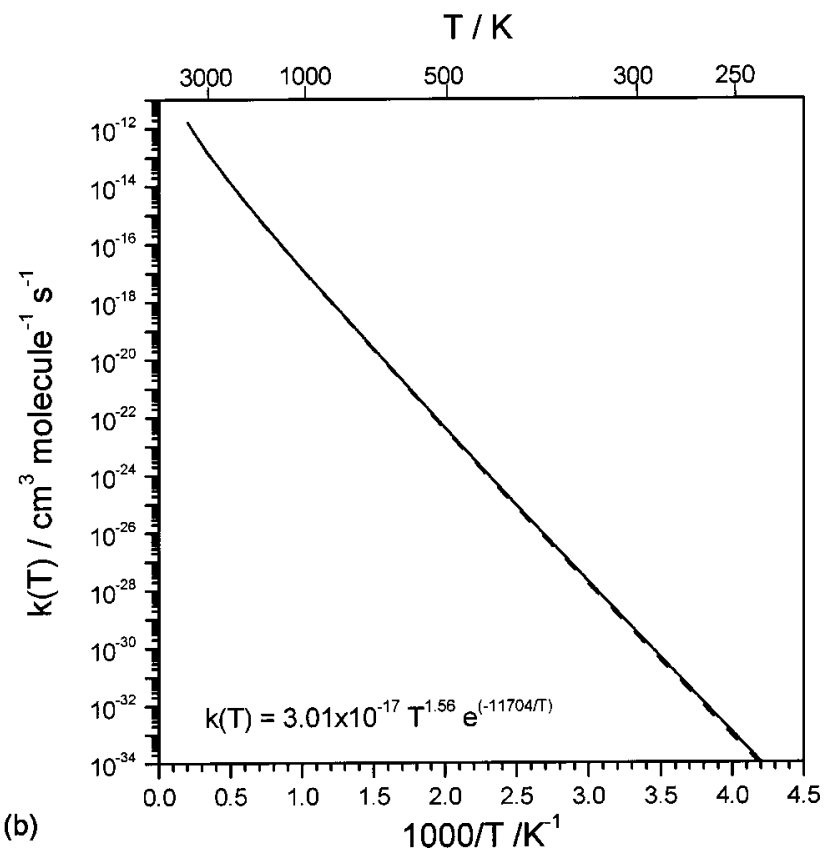

FIG. 6. Arrhenius plots of the calculated and experimental thermal rate constants $\quad(250-5000 \quad \mathrm{~K})$ for $\quad$ (a) $\mathrm{N}\left({ }^{4} S\right)+\mathrm{N}^{\prime} \mathrm{O}\left(X^{2} \Pi\right) \rightarrow \mathrm{O}\left({ }^{3} P\right)$ $+\mathrm{N}_{2}\left(X^{1} \Sigma_{g}^{+}\right)$reaction: ICVT/ $\mu$ OMT values with the new analytical PESs with (solid line) and without (dashed line) spin-orbit correction. Dotted line shows the ICVT/ $\mu$ OMT spin-orbit corrected values using the previous PESs (Refs. 15 and 20). Experimental data showing a typical error bar: $\bigcirc$ (Ref. 7), $\diamond$ (Ref. 2), $\boldsymbol{\Delta}$ (Ref. 3), $\mathbf{\square}$ (Ref. 9), and $\square$ (Ref. 8). (b) $\mathrm{N}\left({ }^{4} S\right.$ ) $+\mathrm{N}^{\prime} \mathrm{O}\left(X^{2} \Pi\right) \rightarrow \mathrm{N}^{\prime}\left({ }^{4} S\right)+\mathrm{NO}\left(X^{2} \Pi\right)$ reaction: ICVT/SCT values with the new analytical PESs with (solid line) and without (dashed line) spin-orbit correction. The $A, B$, and $n$ optimal parameters [Eq. (15)] fitting the ICVT/ $\mu$ OMT spin-orbit corrected values with the new PESs are also indicated $(k$ in $\mathrm{cm}^{3}$ molecule ${ }^{-1} \mathrm{~s}^{-1}$ ).

Finally, we have also computed the thermal rate constants for the reverse reaction $(-1)$ due to the importance of these kinetic data in computational fluid dynamics (CFD) flow simulations for reentry vehicles in Earth's atmosphere. Thus Fig. 7 and Table VII present the thermal rate constants
TABLE VI. Theoretical ICVT/SCT thermal rate constants for the $\mathrm{N}\left({ }^{4} S\right)$ $+\mathrm{N}^{\prime} \mathrm{O}\left(X^{2} \Pi\right) \rightarrow \mathrm{N}^{\prime}\left({ }^{4} S\right)+\mathrm{NO}\left(X^{2} \Pi\right)$ reaction. ${ }^{a}$

\begin{tabular}{rccc}
\hline \hline$T(\mathrm{~K})$ & $k_{2}\left({ }^{3} A^{\prime \prime}\right)$ & $k_{2}\left({ }^{3} A^{\prime}\right)$ & $k_{2}{ }^{\mathrm{b}}$ \\
\hline 200 & $5.13 \times 10^{-54}$ & $7.30 \times 10^{-39}$ & $7.30 \times 10^{-39}$ \\
300 & $2.53 \times 10^{-40}$ & $3.31 \times 10^{-30}$ & $3.31 \times 10^{-30}$ \\
400 & $2.38 \times 10^{-33}$ & $8.65 \times 10^{-26}$ & $8.65 \times 10^{-26}$ \\
500 & $4.04 \times 10^{-29}$ & $4.20 \times 10^{-23}$ & $4.20 \times 10^{-23}$ \\
1000 & $1.74 \times 10^{-20}$ & $1.38 \times 10^{-17}$ & $1.38 \times 10^{-17}$ \\
1500 & $1.66 \times 10^{-17}$ & $1.18 \times 10^{-15}$ & $1.20 \times 10^{-15}$ \\
2000 & $5.68 \times 10^{-16}$ & $1.20 \times 10^{-14}$ & $1.26 \times 10^{-14}$ \\
3000 & $2.21 \times 10^{-14}$ & $1.38 \times 10^{-13}$ & $1.60 \times 10^{-13}$ \\
4000 & $1.51 \times 10^{-13}$ & $5.13 \times 10^{-13}$ & $6.64 \times 10^{-13}$ \\
5000 & $5.02 \times 10^{-13}$ & $1.19 \times 10^{-12}$ & $1.69 \times 10^{-12}$ \\
\hline \hline
\end{tabular}

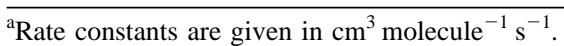

${ }^{\mathrm{b}}$ The total theoretical rate constant $k_{2}$ is calculated using Eq. (10) and the data of the columns on the left.

for each PES and the total rate constant. An excellent agreement with the experimental data ${ }^{8}$ (Table I) is found within the temperature interval $1500-4000 \mathrm{~K}$. The present results with the new PESs also slightly improve the kinetic data derived from previous PESs, as can be seen in Fig. 7. The calculated VTST values are almost independent of the small spin-orbit correction (Fig. 7). VTST rate constants at higher temperatures can also be compared with published QCT (Ref. 20) values derived from our earlier ${ }^{3} A^{\prime \prime}$ PES (Ref. 15) and the previous ${ }^{3} A^{\prime}$ PES (Ref. 20), including the corresponding statistical degeneracy factor for each PES (i.e., 3/9). This QCT study provided a three-parameter expression

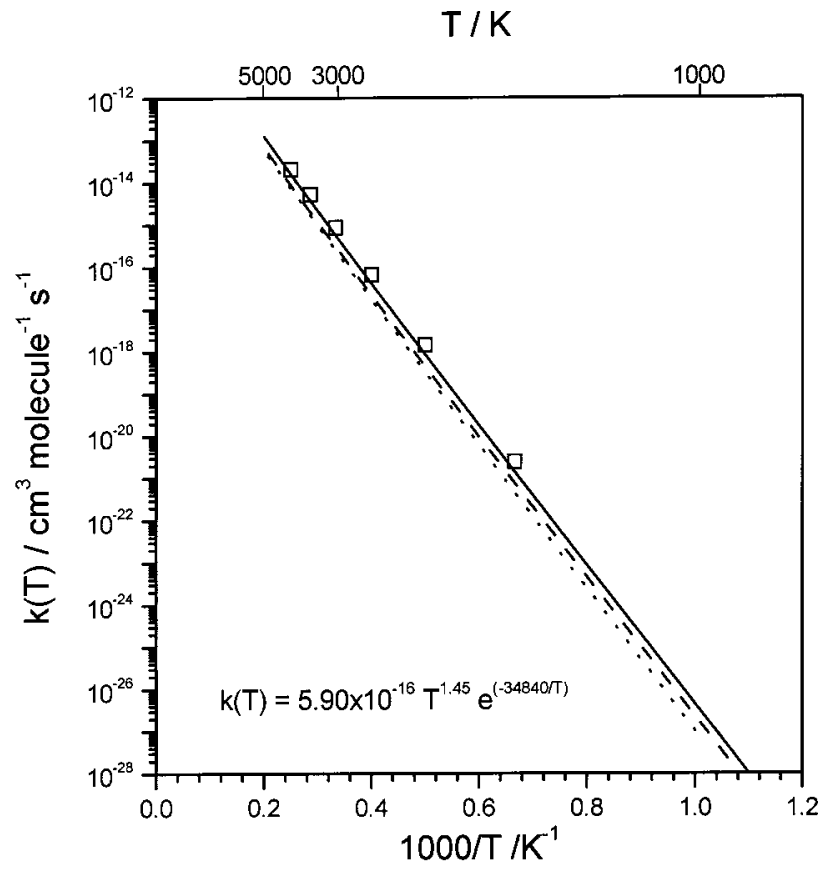

FIG. 7. Arrhenius plots of the calculated and experimental thermal rate constants $(1000-5000 \quad \mathrm{~K})$ for the $\mathrm{O}\left({ }^{3} P\right)+\mathrm{N}_{2}\left(X^{1} \Sigma_{g}^{+}\right) \rightarrow \mathrm{N}\left({ }^{4} S\right)$ $+\mathrm{N}^{\prime} \mathrm{O}\left(X^{2} \Pi\right)$ reaction: ICVT/ $\mu$ OMT values with the new analytical PESs with (solid line) and without (dashed line) spin-orbit correction. Dotted line shows the ICVT/ $\mu$ OMT spin-orbit corrected values using the previous PESs (Refs. 15 and 20). Experimental data ( $\square$ ) with an error lower than size symbol from Ref. 8. The $A, B$, and $n$ optimal parameters [Eq. (15)] fitting the ICVT/ $\mu$ OMT spin-orbit corrected values with the new PESs are also indicated $\left(k\right.$ in $\mathrm{cm}^{3}$ molecule $\left.\mathrm{s}^{-1}\right)$. 
TABLE VII. Theoretical ICVT/ $\mu \mathrm{OMT}$ and experimental thermal rate constants for the $\mathrm{O}\left({ }^{3} P\right)+\mathrm{N}_{2}\left(X^{1} \Sigma_{g}^{+}\right) \rightarrow \mathrm{N}\left({ }^{4} S\right)+\mathrm{NO}\left(X^{2} \Pi\right)$ reaction. ${ }^{a}$

\begin{tabular}{|c|c|c|c|c|c|c|c|}
\hline \multirow[b]{2}{*}{$T(\mathrm{~K})$} & \multicolumn{2}{|c|}{$k_{-1}\left({ }^{3} A^{\prime \prime}\right)$} & \multicolumn{2}{|c|}{$k_{-1}\left({ }^{3} A^{\prime}\right)$} & \multicolumn{3}{|c|}{$k_{-1}$} \\
\hline & New PES & Previous PES ${ }^{b}$ & New PES ${ }^{c}$ & Previous PES ${ }^{d}$ & New PESs ${ }^{e}$ & Previous PESs ${ }^{\mathrm{e}}$ & Experiment $^{\mathrm{f}}$ \\
\hline 600 & $5.11 \times 10^{-38}$ & & $2.49 \times 10^{-41}$ & & $5.12 \times 10^{-38}$ & & \\
\hline 800 & $3.46 \times 10^{-31}$ & & $9.00 \times 10^{-34}$ & & $3.46 \times 10^{-31}$ & & \\
\hline 1000 & $4.44 \times 10^{-27}$ & $1.01 \times 10^{-27}$ & $3.26 \times 10^{-29}$ & $9.92 \times 10^{-31}$ & $4.47 \times 10^{-27}$ & $1.01 \times 10^{-27}$ & $6.98 \times 10^{-27}$ \\
\hline 1500 & $1.36 \times 10^{-21}$ & $4.50 \times 10^{-22}$ & $4.39 \times 10^{-23}$ & $3.96 \times 10^{-24}$ & $1.41 \times 10^{-21}$ & $4.47 \times 10^{-22}$ & $2.44 \times 10^{-21}$ \\
\hline 2000 & $7.78 \times 10^{-19}$ & $3.29 \times 10^{-19}$ & $5.57 \times 10^{-20}$ & $8.74 \times 10^{-21}$ & $8.33 \times 10^{-19}$ & $3.20 \times 10^{-19}$ & $1.45 \times 10^{-18}$ \\
\hline 2500 & $3.61 \times 10^{-17}$ & $1.80 \times 10^{-17}$ & $4.27 \times 10^{-18}$ & $9.37 \times 10^{-19}$ & $4.03 \times 10^{-17}$ & $1.71 \times 10^{-17}$ & $6.66 \times 10^{-17}$ \\
\hline 3000 & $4.76 \times 10^{-16}$ & $2.70 \times 10^{-16}$ & $7.95 \times 10^{-17}$ & $2.19 \times 10^{-17}$ & $5.56 \times 10^{-16}$ & $2.48 \times 10^{-16}$ & $8.56 \times 10^{-16}$ \\
\hline 3500 & $3.06 \times 10^{-15}$ & $1.91 \times 10^{-15}$ & $6.56 \times 10^{-16}$ & $2.13 \times 10^{-16}$ & $3.72 \times 10^{-15}$ & $1.70 \times 10^{-15}$ & $5.31 \times 10^{-15}$ \\
\hline 4000 & $1.25 \times 10^{-14}$ & $8.44 \times 10^{-15}$ & $3.25 \times 10^{-15}$ & $1.19 \times 10^{-15}$ & $1.58 \times 10^{-14}$ & $7.24 \times 10^{-15}$ & $2.08 \times 10^{-14}$ \\
\hline 5000 & $9.27 \times 10^{-14}$ & $7.02 \times 10^{-14}$ & $3.15 \times 10^{-14}$ & $1.39 \times 10^{-14}$ & $1.24 \times 10^{-13}$ & $5.64 \times 10^{-14}$ & $1.41 \times 10^{-13}$ \\
\hline
\end{tabular}

${ }^{a}$ Rate constants are given in $\mathrm{cm}^{-3}$ molecule ${ }^{-1} \mathrm{~s}^{-1}$. Transmission coefficients $\kappa$ are equal to 1 for ${ }^{3} \mathrm{~A}^{\prime \prime}$ PES.

${ }^{\mathrm{b}}$ Using the PES of Ref. 15 and including the electronic statistical degeneracy factor.

${ }^{\mathrm{C}} \mathrm{ICVT} / \mu \mathrm{OMT}$ rate constants calculated on the ${ }^{3} \mathrm{~A}^{\prime} \mathrm{PES}$ with a scaled energy barrier [for reaction (1)] equal to $6.74 \mathrm{kcal} / \mathrm{mol}$ [the ab initio $\mathrm{CBS}$ limit (Ref. 24)].

${ }^{\mathrm{d}}$ Using the PES of Ref. 20 and including the electronic statistical degeneracy factor.

${ }^{\mathrm{e}}$ The total theoretical rate constant $k_{-1}$ is calculated using Eq. (14) and the data of the columns on the left.

${ }^{\mathrm{f}}$ Data from Ref. 8 (1500-4000 K). Italic numbers show two extrapolated values to allow further comparison. Errors are indicated in Table I.

of $k_{-1}(T)=(9.45 \pm 0.32) \times 10^{-12} \times T^{0.42} \times \mathrm{e}^{-42938 \pm 147 / T} \mathrm{~cm}^{3}$ molecule $\mathrm{s}^{-1}$ for the $3000-20000 \mathrm{~K}$ range. Using this equation, we obtain the values of $1.66 \times 10^{-16}, 6.70$ $\times 10^{-15}$, and $6.30 \times 10^{-14} \mathrm{~cm}^{3}$ molecule $\mathrm{e}^{-1} \mathrm{~s}^{-1}$ for 3000 , 4000 , and $5000 \mathrm{~K}$, respectively. These QCT results are consistent with the calculated VTST results using these same PESs (Table VII), which are worse than the present ones, particularly for higher temperatures. At $5000 \mathrm{~K}$ the reported QCT $k\left({ }^{3} A^{\prime \prime}\right) / k\left({ }^{3} A^{\prime}\right)$ ratio ${ }^{20}$ was 15 as compared with the VTST value of 5.1 for both previous PESs, which differ from the small value (2.9) obtained with the new PESs. Therefore, we conclude that the excited PES $\left({ }^{3} A^{\prime}\right)$ must be included in kinetic and dynamic studies of reaction $(-1)$ at temperatures lower than those predicted in the QCT study $(T>8000 \mathrm{~K})$. Whereas the QCT $k_{-1}\left({ }^{3} A^{\prime \prime}\right) / k_{-1}\left({ }^{3} A^{\prime}\right)$ ratio is 2 at $12000 \mathrm{~K}$, the same VTST value with the new PESs is obtained at $7800 \mathrm{~K}$.

QCT and quantum wave-packet dynamic studies using these new PESs are in progress in our group to provide more detailed information of the kinetics and dynamics of all reaction channels.

\section{CONCLUSIONS AND REMARKS}

In this work we have built new analytical fits of the ground PES $\left({ }^{3} A^{\prime \prime}\right)$ and the excited PES $\left({ }^{3} A^{\prime}\right)$ involved in the $\mathrm{N}\left({ }^{4} S\right)+\mathrm{NO}\left(X^{2} \Pi\right)$ reaction $[\mathrm{N}$-abstraction (1) and O-abstraction (2) channels] and also for the reverse, $(-1)$, using $a b$ initio data reported in paper I (Ref. 24) along with new extensive grids of high-level $a b$ initio points [CASPT2 $(10,9)$ G2/cc-pVTZ calculations] computed in the present work. Diatomic $D_{e}$ and $R_{e}$ spectroscopic data were also introduced to better account for the exoergicity of reaction (1). The final RMSD for the ${ }^{3} A^{\prime \prime}$ surface was equal to $1.44 \mathrm{kcal} / \mathrm{mol}$ for the $\mathrm{NN}^{\prime} \mathrm{O}$ region and $2.59 \mathrm{kcal} / \mathrm{mol}$ for the $\mathrm{NON}^{\prime}$ region, with a global RMSD of $1.80 \mathrm{kcal} / \mathrm{mol}$. For the ${ }^{3} A^{\prime}$ surface, we obtained a final RMSD equal to 1.61 $\mathrm{kcal} / \mathrm{mol}$ for the $\mathrm{NN}^{\prime} \mathrm{O}$ region and $2.85 \mathrm{kcal} / \mathrm{mol}$ for the
$\mathrm{NON}^{\prime}$ region, with a global RMSD of $2.28 \mathrm{kcal} / \mathrm{mol}$. These RMSDs were well below the estimated $a b$ initio errors.

Thermal rate constants were calculated for both direct reaction channels and for the reverse reaction by means of the variational transition-state theory with the inclusion of a semiclassical tunneling correction. Theoretical rate constants for reaction (1) were in excellent agreement with experimental data at low to moderate and also at very high temperatures (200-5000 K), significantly improving the results obtained by using previous PESs. The contribution of the ${ }^{3} A^{\prime}$ PES to the total rate constant was small even at high temperatures (e.g., only $10.8 \%$ at $2500 \mathrm{~K}$ ). The main enhancement in the rate constants arises from the new ${ }^{3} A$ " PES, which gives rate constants higher than the previous PES.

The VTST calculation for reaction (2) showed that the main contribution to the total rate constant was due to the ${ }^{3} A^{\prime}$ PES, differing from the behavior in reaction (1). Despite $k_{2}$ values much lower than $k_{1}$ values at low and moderate temperatures $(T<1000 \mathrm{~K})$, the present results have shown that the O-abstraction channel accounts for $3.0 \%$ of the total reaction at $5000 \mathrm{~K}$, which is consistent with the limited available experimental information, which indicates that the branching ratio $\left[k_{2} /\left(k_{1}+k_{2}\right)\right]$ should be between $0 \%$ and $20 \%$, depending on the $\mathrm{N}$-atom translational energy.

Calculated VTST rate constants for the reverse reaction $(-1)$ were also in very good agreement with the experimental data within the temperature interval 1500-5000 K. The present results with the new PESs also improved slightly the kinetic data derived by using the previous PESs. Hence the ${ }^{3} A$ ' PES should be included in kinetic and dynamic studies of this reverse reaction for temperatures much lower than those predicted in previous QCT studies, although its contribution to the total $k_{-1}$ is low (e.g., $6.7 \%$ at $2000 \mathrm{~K}$ ).

The new analytical PESs accurately describe the NNO $C_{s}$ regions and also the NON $C_{2 v}$ and $C_{s}$ regions, which make them valuable for use in theoretical studies of all three reaction processes. Dynamic and kinetic studies with the new PESs using the QCT method and a quantum wave-packet 
dynamic approach are in progress in our group to further study the reactions (1) and (2), especially regarding the dynamical properties derived from each PES.

\section{ACKNOWLEDGMENTS}

This work has been supported by the Spanish Ministry of Education and Culture (Project No. PB98-1209-C02-01) and the Spanish Ministry of Science and Technology (Project Nos. BQU2002-03351 and BQU2002-04269-C02-02). Financial support from the European Union (INTAS Project No. 99-00701) and the "Generalitat" (Autonomous Government) of Catalonia (Project No. 2001SGR 00041) is also acknowledged. P.G. thanks the "Universitat de Barcelona" for a predoctoral research grant. The authors are grateful to the "Center de Computació i Comunicacions de Catalunya ( $\mathrm{C}^{4}$-CESCA/CEPBA)" for providing part of the computer time.

${ }^{1}$ M. W. Chase, Jr., C. A. Davies, J. R. Downey, Jr., D. J. Frurip, R. A. McDonald, and A. N. Syverud, J. Phys. Chem. Ref. Data Suppl. 14, 1 (1985).

${ }^{2}$ D. E. Siskind and D. W. Rusch, J. Geophys. Res. 97, 3209 (1992).

${ }^{3}$ P. O. Wennberg, J. G. Anderson, and D. K. Weisenstein, J. Geophys. Res. 99, 18839 (1994).

${ }^{4}$ P. Warneck, Chemistry of the Natural Atmosphere (Academic, San Diego, 1998), Chap. 3.

${ }^{5}$ G. Marston, Chem. Soc. Rev. 25, 33 (1996).

${ }^{6}$ T. Kurotaki, AIAA paper No. 2000-2366, 2000.

${ }^{7}$ M. A. A. Clyne and I. S. McDermid, J. Chem. Soc., Faraday Trans. 171 , 2189 (1975).

${ }^{8}$ D. L. Baulch, C. J. Cobos, R. A. Cox, G. Hayman, Th. Just, J. A. Kerr, T. Murrells, M. J. Pilling, J. Troe, R. W. Walker, and J. Warnatz, J. Phys. Chem. Ref. Data 23, 847 (1994).

${ }^{9}$ W. B. DeMore, D. M. Golden, R. F. Hampson, M. J. Kurylo, C. J. Howard, A. R. Ravishankara, C. E. Kolb, and M. J. Molina, Chemical Kinetics and Photochemical Data for Use in Stratospheric Modelling, Evaluation 12, JPL Publ. 97-4 (Jet Propulsion Laboratory, Pasadena, CA, 1997).

${ }^{10}$ G. Black, R. L. Sharpless, and T. G. Slanger, J. Chem. Phys. 58, 4792 (1973).

${ }^{11}$ J. E. Morgan and H. I. Schiff, Can. J. Phys. 41, 903 (1963).

${ }^{12}$ J. E. Morgan, L. F. Phillips, and H. I. Schiff, Discuss. Faraday Soc. 33, 118 (1962)
${ }^{13}$ M. Gilibert, A. Aguilar, M. González, F. Mota, and R. Sayós, J. Chem. Phys. 97, 5542 (1992).

${ }^{14}$ S. P. Walch and R. L. Jaffe, J. Chem. Phys. 86, 6946 (1987); AIP Document No. PAPSJCPSA-86-6946-10.

${ }^{15}$ M. Gilibert, A. Aguilar, M. González, and R. Sayós, J. Chem. Phys. 99, 1719 (1993).

${ }^{16}$ A. Aguilar, M. Gilibert, X. Giménez, M. González, and R. Sayós, J. Chem. Phys. 103, 4496 (1995).

${ }^{17}$ R. Sayós, A. Aguilar, M. Gilibert, and M. González, J. Chem. Soc., Faraday Trans. 1 89, 3223 (1993).

${ }^{18}$ J. W. Duff and R. D. Sharma, Geophys. Res. Lett. 23, 2777 (1996).

${ }^{19}$ J. W. Duff and R. D. Sharma, Chem. Phys. Lett. 265, 404 (1997).

${ }^{20}$ D. Bose and G. V. Candler, J. Chem. Phys. 104, 2825 (1996).

${ }^{21}$ D. Bose and G. V. Candler, J. Thermophys. Heat Transfer 10, 148 (1996).

${ }^{22}$ J. Dubrin, C. Mackay, and R. Wolfgang, J. Chem. Phys. 44, 2208 (1966).

${ }^{23}$ R. Iwata, A. Ferrieri, and A. P. Wolf, J. Phys. Chem. 90, 6722 (1986).

${ }^{24}$ P. Gamallo, M. González, and R. Sayós, J. Chem. Phys. 118, 10602 (2003).

${ }^{25}$ B. O. Roos, P. R. Taylor, and P. E. M. Siegbahn, Chem. Phys. 48, 157 (1980).

${ }^{26}$ B. O. Roos, in Advances in Chemical Physics: Ab Initio Methods in Quantum Chemistry_II, edited by K. P. Lawley (Wiley, Chichester, 1987), Vol. LXIX, p. 399

${ }^{27}$ T. H. Dunning, Jr., J. Chem. Phys. 90, 1007 (1989).

${ }^{28} \mathrm{~K}$. Andersson, Theor. Chim. Acta 91, 31 (1995).

${ }^{29}$ K. Andersson, M. R. A. Blomberg, M. P. Fülscher et al., computer code MOLCAS 4.1, Lund University, Sweden, 1998.

${ }^{30}$ J. N. Murrell, S. Carter, S. C. Farantos, P. Huxley, and A. J. C. Varandas, Molecular Potential Energy Surfaces (Wiley, New York, 1984).

${ }^{31}$ M. González and R. Sayós, computer code DIATOMFIT (unpublished).

${ }^{32}$ R. Sayós and M. González, computer code SM3FIT (unpublished).

${ }^{33}$ M. González, R. Valero, and R. Sayós, J. Chem. Phys. 113, 10983 (2000).

${ }^{34}$ M. González, I. Miquel, and R. Sayós, J. Chem. Phys. 115, 2530 (2001).

${ }^{35}$ R. Sayós, C. Oliva, and M. González, J. Chem. Phys. 117, 670 (2002).

${ }^{36}$ K. P. Huber and G. Herzberg, Molecular Spectra and Molecular Structure IV. Constants of Diatomic Molecules (Van Nostrand Reinhold, New York, 1979).

${ }^{37}$ R. Sayós, C. Oliva, and M. González, J. Chem. Phys. 115, 1287 (2001).

${ }^{38}$ D. G. Truhlar, B. C. Garrett, and S. J. Klippenstein, J. Phys. Chem. 100, 12771 (1996)

${ }^{39}$ R. Steckler, Y. Chuang, E. L. Coitiño, W. Hu, Y. Liu, G. C. Lynch, K. A. Nguyen, C. F. Jackels, M. Z. Gu, I. Rossi, P. Fast, S. Clayton, V. S. Melissas, B. C. Garrett, A. D. Isaacson, and D. G. Truhlar, computer code POLYRATE, version 7.0, Department of Chemistry and Supercomputer Institute, University of Minnesota, 1996.

${ }^{40}$ G. I. Gellene, J. Chem. Educ. 72, 196 (1995).

${ }^{41}$ R. Sayós, J. Hijazo, M. Gilibert, and M. González, Chem. Phys. Lett. 284, 101 (1998). 